\title{
DYSREGULATION OF THE ENDOCANNABINOID SIGNALING SYSTEM IN THE CEREBELLUM AND BRAINSTEM IN A TRANSGENIC MOUSE MODEL OF SPINOCEREBELLAR ATAXIA TYPE-3
}

\author{
CARMEN RODRÍGUEZ-CUETO, \\ MARILUZ HERNÁNDEZ-GÁLVEZ, ${ }^{a, b, c, d}$ \\ CECILIA J. HILLARD, ${ }^{e}$ PATRICIA MACIEL,, $\mathrm{f}$ \\ LUIS GARCÍA-GARCÍA, ${ }^{,, i}$ SARA VALDEOLIVAS, \\ MIGUEL A. POZO, ${ }^{\mathrm{h}, \mathrm{j}}$ JOSÉ A. RAMOS, ${ }^{\mathrm{a}, \mathrm{b}, \mathrm{c}}$ \\ MARÍA GÓMEZ-RUIZ ${ }^{\mathrm{a}, \mathrm{b}, \mathrm{c}, \mathrm{d} *}$ AND \\ JAVIER FERNÁNDEZ-RUIZ ${ }^{\mathrm{a}, \mathrm{b}, \mathrm{c} *}$ \\ ${ }^{a}$ Instituto Universitario de Investigación en Neuroquímica, \\ Departamento de Bioquímica y Biología Molecular, Facultad \\ de Medicina, Universidad Complutense, Madrid, Spain \\ ${ }^{\mathrm{b}}$ Centro de Investigación Biomédica en Red de \\ Enfermedades Neurodegenerativas, Madrid, Spain \\ c Instituto Ramón y Cajal de Investigación Sanitaria, Madrid, Spain \\ ${ }^{d}$ Departamento de Psicobiología, Facultad de Psicología, \\ Universidad Complutense, Madrid, Spain \\ ${ }^{\mathrm{e}}$ Department of Pharmacology and Toxicology, Medical College of \\ Wisconsin, Milwaukee, WI, USA \\ ${ }^{\mathrm{f}}$ Life and Health Sciences Research Institute (ICVS), \\ School of Health Sciences, University of Minho, Braga, Portugal \\ 'ICVS/3B's-PT Government Associate Laboratory, \\ Braga/Guimaraes, Portugal \\ h Unidad de Cartografía Cerebral, Instituto Pluridisciplinar, \\ Universidad Complutense, Madrid, Spain \\ ' Departamento de Farmacología, Facultad de Farmacia, Universidad \\ Complutense, Madrid, Spain \\ 'Departamento de Fisiología, Facultad de Medicina, Universidad \\ Complutense, Madrid, Spain
}

Abstract-Spinocerebellar ataxia type-3 (SCA-3) is a rare disease but it is the most frequent type within the autosomal dominant inherited ataxias. The disease lacks an effective treatment to alleviate major symptoms and to modify

${ }^{*}$ Corresponding authors. Address: Department of Biochemistry and Molecular Biology, Faculty of Medicine, Complutense University, 28040 Madrid, Spain.

E-mail addresses: msgr@med.ucm.es (M. Gómez-Ruiz), jjfr@med. ucm.es (J. Fernández-Ruiz).

Abbreviations: ABHD12, $\alpha / \beta$-hydrolase domain-containing 12; 2-AG, 2-arachidonoylglycerol; CNS, Central Nervous System; Ct, threshold cycle; DAGL, diacylglycerol lipase; FAAH, fatty acid amide hydrolase; $\left[{ }^{18} \mathrm{~F}\right] \mathrm{FDG}, \quad 2$-deoxy-2-[18 $\left.\mathrm{F}\right]$ fluoro-D-glucose; GLAST, glutamateaspartate transporter; GLT-1, glutamate transporter-1; IL-1 $\beta$, interleukin-1 $\beta$; MAGL, monoacylglycerol lipase; MRI, magnetic resonance image; NAPE-PLD, N-arachidonoylphosphatidylethanola mine phospholipase D; NSE, neuron-specific enolase; OEA, oleylethanolamide; PBS, phosphate-buffered saline; PEA, palmitoylethanolamide; PET, positron emission tomography; PET/CT, $\mathrm{PET} /$ computed tomography; polyQ, polyglutaminopathies; PPAR, peroxisome-proliferator activating receptor; SCA, spinocerebellar ataxia; SCA-3, spinocerebellar ataxia type-3; TNF- $\alpha$, tumor necrosis factor- $\alpha$.

http://dx.doi.org/10.1016/j.neuroscience. 2016.09.046

0306-4522/@ 2016 IBRO. Published by Elsevier Ltd. All rights reserved. disease progression. Our recent findings that endocannabinoid receptors and enzymes are significantly altered in the post-mortem cerebellum of patients affected by autosomaldominant hereditary ataxias suggest that targeting the endocannabinoid signaling system may be a promising therapeutic option. Our goal was to investigate the status of the endocannabinoid signaling system in a transgenic mouse model of SCA-3, in the two CNS structures most affected in this disease - cerebellum and brainstem. These animals exhibited progressive motor incoordination, imbalance, abnormal gait, muscle weakness, and dystonia, in parallel to reduced in vivo brain glucose metabolism, deterioration of specific neuron subsets located in the dentate nucleus and pontine nuclei, small changes in microglial morphology, and reduction in glial glutamate transporters. Concerning the endocannabinoid signaling, our data indicated no changes in $C B_{2}$ receptors. By contrast, $C_{1} B_{1}$ receptors increased in the Purkinje cell layer, in particular in terminals of basket cells, but they were reduced in the dentate nucleus. We also measured the levels of endocannabinoid lipids and found reductions in anandamide and oleoylethanolamide in the brainstem. These changes correlated with an increase in the FAAH enzyme in the brainstem, which also occurred in some cerebellar areas, whereas other endocannabinoid-related enzymes were not altered. Collectively, our results in SCA-3 mutant mice confirm a possible dysregulation in the endocannabinoid system in the most important brain structures affected in this type of ataxia, suggesting that a pharmacological manipulation addressed to correct these changes could be a promising option in SCA-3. (C) 2016 IBRO. Published by Elsevier Ltd. All rights reserved.

Key words: cannabinoids, endocannabinoid signaling system, autosomal-dominant inherited ataxias, spinocerebellar ataxia-3, Machado-Joseph disease, motor incoordination.

\section{INTRODUCTION}

Autosomal-dominant spinocerebellar ataxias (SCAs) are a group of inherited neurodegenerative disorders, in which the most prevalent cases belong to the family of polyglutaminopathies (polyQ), that also includes Huntington's disease (Durr, 2010; Klockgether, 2011; Seidel et al., 2012; Rüb et al., 2013). The most prevalent type within SCAs is SCA-3 or Machado-Joseph disease, which is caused by a polyglutamine expansion in a protein identified in the disease and called ataxin-3 (Paulson, 2012). The key neuropathological hallmark in SCA-3, 
and in most of polyQ disorders, is the presence of intranuclear inclusions, which are linked to protein misfolding, failed or incomplete proteolysis, and deposition and formation of protein aggregates (Paulson, 2012). This is a key point in SCA-3 given the role of normal ataxin-3 in the control of ubiquitination/ deubiquitination balance (Rüb et al., 2013). These aggregates are thought to contribute to the pathogenic process by eliciting transcriptional dysregulation, but also mitochondrial failure, excitotoxicity, altered calcium homeostasis, oxidative stress and local inflammatory events (Matilla-Dueñas et al., 2012; Orr, 2012), which are ultimately responsible of the death of specific neuronal subpopulations located in some central nervous system (CNS) structures, mainly the cerebellum, the brainstem and the striatum (Taroni and DiDonato, 2004; Fratkin and Vig, 2012; MatillaDueñas, 2012). This specificity in neuronal death occurs despite the ubiquitous expression of mutant ataxin-3 and explains that, clinically, patients present a broadspectrum of neurological abnormalities, which include primary cerebellar symptoms, such as progressive loss of motor coordination and gait anomalies (Riess et al., 2008; Matilla-Dueñas, 2012), and non-cerebellar symptoms such as peripheral amyotrophy (muscle atrophy), oculomotor impairment, spasticity and extrapyramidal signs, e.g. rigidity and dystonia, typically found at advanced phases but also present at earlier stages (Matilla-Dueñas et al., 2012; Jacobi et al., 2013; Rüb et al., 2013).

The disease has no cure and also lacks effective treatments that alleviate major symptoms or modify disease progression (Rüb et al., 2013), although several strategies are under investigation including: (i) inhibitors of histone deacetylases (e.g. sodium butyrate (Chou et al., 2011)) to correct transcriptional dysregulation; (ii) interference RNA to reduce the translation of the mutated protein (Alves et al., 2010); and (iii) activation of autophagy to eliminate protein aggregates (Menzies et al., 2010; Nascimento-Ferreira et al., 2013; Silva-Fernandes et al., 2014). Compared to Huntington's disease, the most prevalent polyQ disorder, which has been investigated for the possible benefits of cannabinoid-based therapies as disease modifiers (recently reviewed in (Fernández-Ruiz et al., 2015)), SCA-3 and the other autosomal-dominant inherited ataxias have not been investigated yet for this possibility, despite the well-demonstrated neuroprotective effects of these compounds (Fernández-Ruiz et al., 2010, 2011, 2015). Only two studies conducted in our laboratory have recently addressed the status of endocannabinoid receptors and enzymes in the post-mortem cerebellum of SCA patients (Rodríguez-Cueto et al., 2014a,b). One of these studies described that $\mathrm{CB}_{1}$ and $\mathrm{CB}_{2}$ receptors become up-regulated in SCA patients (Rodríguez-Cueto et al., 2014a). This includes the overexpression of both receptors in neuronal subpopulations in which they are not usually located or their expression is too weak, i.e. Purkinje cells (Rodríguez-Cueto et al., 2014a). Both receptors, but particularly the $\mathrm{CB}_{2}$ receptors, were also found in glial elements, e.g. reactive microglia, macrophages and astrocytes, in control subjects experiencing a significant elevation in the case of SCA patients
(Rodríguez-Cueto et al., 2014a). The fact that the two major receptors for endocannabinoids are altered in SCA patients supports the idea that those cannabinoids selectively targeting the $\mathrm{CB}_{1}$ (they are effective in reducing excitotoxicity (Fernández-Ruiz et al., 2010, 2011)) and/or the $\mathrm{CB}_{2}$ receptor (they are active on glial activation and associated local inflammatory events (FernándezRuiz et al., 2007, 2010)) may be possibly beneficial in SCAs. These effects may be reinforced by other neuroprotective properties of cannabinoids, for example, their activity against oxidative injury, their capability to act on several transcription factors (e.g. Nrf-2, NFKB) or to bind the peroxisome-proliferator activating receptors (PPARs), all of them already demonstrated in numerous chronic neurodegenerative disorders (Fernández-Ruiz et al., 2010, 2013). In a further study (Rodríguez-Cueto et al., 2014b), we analyzed endocannabinoid-inactivating enzymes, e.g. fatty acid amide hydrolase (FAAH), monoacyl-glycerol lipase (MAGL). We were able to detect immunoreactivity for the FAAH and MAGL enzymes in the granular layer, Purkinje cells, neurons of the dentate nucleus and areas of white matter in the cerebellum of patients at levels notably higher than control subjects, and, using double-labeling procedures, we found co-localization of FAAH and MAGL with calbindin, supporting the presence of these enzymes in Purkinje neurons (Rodríguez-Cueto et al., 2014b). The interest of these two enzymes is that they are also susceptible to be pharmacologically manipulated, so that their inhibitors may become in potential disease-modifying therapies in these disorders. Indirect support to the therapeutic potential of the endocannabinoid system in SCAs comes from studies identifying mutations in $\alpha / \beta$-hydrolase domain-containing 12 (ABHD12) gene, which encodes an enzyme also involved in endocannabinoid catabolism (Fiskerstrand et al., 2010; Chen et al., 2013). Such mutations have been related to a clinical phenotype that includes ataxia (associated with cerebellar atrophy) and ocular abnormalities, although with variable occurrence and extent (Fiskerstrand et al., 2010; Chen et al., 2013). In addition, the genetic ablation of this enzyme in mice was associated with the development of ataxia and muscle weakness, accompanied by microglial activation in numerous CNS structures (Blankman et al., 2013).

The problem with the changes found in the endocannabinoid signaling in post-mortem tissues from SCA patients is that they correspond to a very advanced stage of the disease, when patients died, and it is unclear whether they also exist (or are different) during the different stages in the disease progression (e.g. presymptomatic, early symptomatic or stable symptomatic stages). To clarify this question would be critical to elucidate, for example, whether the changes in endocannabinoid signals may be part of the pathogenic process. Therefore, the issue would need to be investigated in experimental models of SCA-3, or other autosomal-dominant inherited ataxias, as a necessary step for the design of reliable future cannabinoid-based therapies. Such studies do not exist to date, in part due to the lack of useful models of these disorders. In this respect, a transgenic mouse model of SCA-3 has been 
recently developed which reproduces many of the neurological and neuropathological signs of the disease, following a gradual and progressive pattern with expression of mutant ataxin-3 at near endogenous levels (Silva-Fernandes et al., 2014). We have used these mice for investigating the changes in the endocannabinoid signaling in key CNS structures related to the symptoms and neuropathological lesions observed in SCA-3. We first characterized the progression of neurological deficits in these mice using different behavioral tests useful to detect anomalies in motor coordination, balance, motor strength and dystonia (e.g. rotarod, balance beam, hanging wire, clasping, footprinting), and we correlated these changes with different neuropathological signs reflecting neuronal malfunctioning or death in these CNS structures. With these neurological and neuropathological data, we defined three different stages for this study: (i) a presymptomatic/early symptomatic stage (up to 16 weeks); (ii) a stable symptomatic stage (up to 32 weeks); and (iii) an advanced stage (up to 56 weeks and later on), in which we recorded the changes in endocannabinoid ligands and related signaling lipids, and their receptors and enzymes, using different biochemical and histological approaches, and concentrating in the two key CNS structures (cerebellum, brainstem) affected in the disease (Fratkin and Vig, 2012; Seidel et al., 2016).

\section{EXPERIMENTAL PROCEDURES}

\section{Animals and sampling}

All experiments were conducted with pCMVMJD135Q transgenic and non-transgenic littermate sibling mice bred in our animal facilities from initial breeders provided by Patricia Maciel (University of Minho, Braga, Portugal; Silva-Fernandes et al., 2014). Offspring were genotyped for the transgene containing the ataxin-3 mutation (around 135Q) following the procedure described previously (Silva-Fernandes et al., 2014). All animals were housed in a room with controlled photoperiod (08:0020:00 light) and temperature $\left(22 \pm 1^{\circ} \mathrm{C}\right)$ with free access to standard food and water. All experiments were conducted according to local and European rules (directive 2010/63/EU), followed the ARRIVE guidelines and were approved by the "Comité de Experimentación Animal" of our university (ref. CEA-UCM 56/2012). We used nontransgenic and pCMVMJD135Q transgenic male mice for longitudinal studies aimed first at characterizing the appearance of the pathological phenotype at behavioral, biochemical and histological levels, and second to analyze a possible dysregulation in the endocannabinoid signaling. A series of behavioral tests to identify deficits in motor coordination and balance, and motor weakness and/or dystonia, were employed always with at least six animals per experimental condition (genotype and age). This included hanging wire, balance beam, footprinting and rotarod tests, and analysis of clasping behavior which is a marker of dystonia. Behavioral analyses were performed within 7-55 weeks after birth, which allowed for the establishment of three different disease stages: (i) a presymptomatic/early symptomatic stage that included animals up to 16 weeks after birth, which, in agreement with previous studies (Silva-Fernandes et al., 2014), was characterized by loss of muscle strength in the hanging wire test; (ii) a stable symptomatic stage that included animals up to the age of 32 weeks after birth, which included impaired performance in the balance beam and the rotarod, indicating problems of balance and motor coordination, as also seen previously (Silva-Fernandes et al., 2014); and (iii) an advanced stage at ages up to 56 weeks after birth that included significant deficiencies in gait and dystonia, reflected in a worsened performance in the footprinting tests and the occurrence of clasping behavior, respectively. During this period, animals were also subjected at two ages ( 21 and 43 weeks after birth) to an in vivo analysis of glucose utilization in the CNS using a PET procedure.

Immediately after the last behavioral recording, some of the animals were transcardially perfused with saline followed by fresh $4 \%$ paraformaldehyde in $0.1 \mathrm{M}$

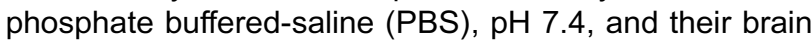
was collected and post-fixed for one day at $4{ }^{\circ} \mathrm{C}$, then immersed in $30 \%$ of sucrose solution for another day, and finally stored at $-80^{\circ} \mathrm{C}$ for Nissl staining and immunohistochemical analysis. In other mice, brains were collected and the cerebellum and brainstem were dissected and rapidly frozen in dry ice, and stored at $-80^{\circ} \mathrm{C}$ for biochemical analysis (qRT-PCR and Western blotting), as well as for analysis of endocannabinoid concentrations. In all cases, the animal weight was recorded during the whole period of disease progression. This also included the examination of the animal physical appearance which allowed detecting, for example, the occurrence of kyphosis at the advanced stages. A separate group of wild-type and pCMVMJD135Q transgenic male mice were used to quantify animal survival using Kaplan-Meier analysis. In most of experiments, a range of 6-8 animals were used per experimental group.

\section{Behavioral recording}

Rotarod test. We used a LE8200 device (Panlab, Barcelona, Spain). After a period of acclimation and training (first session: 0 rpm for $30 \mathrm{~s}$; second and third sessions: $4 \mathrm{rpm}$ for $60 \mathrm{~s}$, with periods of $10 \mathrm{~min}$ between sessions) conducted $30 \mathrm{~min}$ before, animals were tested with an acceleration from 4 to $40 \mathrm{rpm}$ over a period of $300 \mathrm{~s}$. Mice were tested for three consecutive trials with a rest period of approximately $15 \mathrm{~min}$ between trials and the mean of three trials was calculated.

Hanging wire test. Mice were placed on a wire cage top, which was slowly inverted and suspended at approximately $30 \mathrm{~cm}$ to the floor. The latency by each animal to fall from the cage top was recorded. The process was repeated three times and the mean of the three trials calculated.

Balance beam. Motor coordination and balance were assessed by measuring the ability of the mice to stay upright and walk across an elevated $10-\mathrm{mm}$ round diameter wood beam. The test was performed over two 
consecutive days: first day for training and second day for testing. The time spent by each animal to travel a distance of $80 \mathrm{~cm}$ in the beam was recorded. The process was repeated three times and the mean of the three trials calculated.

Footprinting test. To detect abnormalities in gait, front and hind paws were dipped in red and blue water-based dye, respectively. Mice were then placed on a sheet of white paper and allowed to walk through a tunnel, leaving their footprint pattern on the white paper.

Hindlimb clasping. Mice were suspended by the tail, so that their body dangled in the air facing downward. Hindlimb position was observed with the mice lifted by the tail for $30 \mathrm{~s}$ and animals were scored according to the following scale: (i) score $=0$ if the hindlimbs are consistently splayed outward, away from the abdomen; (ii) score $=1$ if one hindlimb is retracted toward the abdomen; (iii) score $=2$ if both hindlimbs are partially retracted toward the abdomen; and (iv) score $=3$ if both hindlimbs are entirely retracted and touching the abdomen.

\section{In vivo analysis of glucose metabolism: $\left[{ }^{18} \mathrm{~F}\right] \mathrm{FDG}$ PET imaging}

To evaluate the regional brain metabolic activity, PET with the radiotracer $\left[{ }^{18} \mathrm{~F}\right] \mathrm{FDG}$ was performed. Briefly, mice were fasted, to minimize the influence of glucemia, for at least $12 \mathrm{~h}$ previous to be i.p. injected with approximately $11.1 \mathrm{MBq}$ of $\left[{ }^{18} \mathrm{~F}\right] \mathrm{FDG}$ (Instituto Tecnológico PET, Madrid, Spain). After an uptake period of $45 \mathrm{~min}$, mice were scanned with a smallanimal hybrid PET/CT (computed tomography) device (Albira ARS scanner, Oncovision, Valencia, Spain) under $2 \%$ isoflurane anesthesia. PET acquisition time was $30 \mathrm{~min}$ and it was immediately followed by CT scanning. After reconstruction of the PET and CT images, these were co-registered to a magnetic resonance image (MRI) template for the mouse brain, in which the brain regions were delineated. To this aim, the CT image was first co-registered to the MRI template and the mathematical transformation was saved. Then, this transformation was applied to its own fused PET image. This step allows the right matching of the PET image with the mouse brain MRI template. All these steps were carried out using PMOD 3.0 software (PMOD Technologies Ltd., Zurich, Switzerland). As index of regional metabolic activity, we used the standard uptake value (SUV), which is currently the most used quantification index using $\left[{ }^{18} \mathrm{~F}\right] \mathrm{FDG} P E T$ imaging for small animals (Deleye et al., 2014). It represents the ratio of the regional radioactivity concentration measured by the PET scanner and the actual injected dose (corrected for radiotracer decay at the time of the injection) divided by the body weight of the animal.

\section{Biochemical analyses}

Real-time $q R T-P C R$ analysis. Total RNA was extracted using SurePrep ${ }^{\mathrm{TM}}$ RNA/Protein Purification kit
(Fisher BioReagents, Fair Lawn, NJ, USA). The total amount of RNA was quantitated by spectrometry at $260 \mathrm{~nm}$ and its purity was evaluated by the ratio between the absorbance values at 260 and $280 \mathrm{~nm}$, whereas its integrity was confirmed in agarose gels. To prevent genomic DNA contamination, DNA was removed and single-stranded complementary DNA was synthesized from $1 \mu \mathrm{g}$ of total RNA using a commercial kit (Rneasy Mini Quantitect Reverse Transcription, Qiagen, Izasa, Madrid, Spain). The reaction mixture was kept frozen at $-20{ }^{\circ} \mathrm{C}$ until enzymatic amplification. Quantitative real-time PCR assays were performed using TaqMan Gene Expression Assays (Applied Biosystems, Foster City, CA, USA) to quantify mRNA levels for $\mathrm{CB}_{1}$ receptor (ref. Mm00432621_s1), $\mathrm{CB}_{2}$ receptor (ref. Mm00438286_m1), FAAH (ref. Mm00515684_m1), MAGL (ref. Mm00449274_m1), DAGL (ref. Mm00813830_m1), NAPE-PLD (ref. Mm00724596_m1), calbindin (ref. Mm00486647_m1), NSE (ref. Mm00469062 m1), BDNF (ref. Mm01334042 m1), IL-1 $\beta$ (ref. Mm00434228_m1), TNF- $\alpha$ (ref. Mm99999068_m1), GLAST (ref. Mm00600697_m1) and GLT-1 (ref. Mm00441457_m1) using GAPDH expression (ref. Mm99999915_g1) as an endogenous control gene for normalization. The PCR assay was performed using the 7300 Fast Real-Time PCR System (Applied Biosystems, Foster City, CA, USA) and the threshold cycle (Ct) was calculated by the instrument's software (7300 Fast System, Applied Biosystems, Foster City, CA, USA).

Western blot analysis. Purified protein fractions were isolated using SurePrep ${ }^{\mathrm{TM}}$ RNA/Protein Purification kit (Fisher BioReagents, Fair Lawn, NJ, USA). Subsequently, $20 \mu \mathrm{g}$ of protein was boiled for $5 \mathrm{~min}$ in Laemmli SDS loading buffer (10\% glycerol, 5\% SDS, $5 \% \beta$-mercaptoethanol, $0.01 \%$ bromophenol blue and $125 \mathrm{mM}$ TRIS- $\mathrm{HCl}$, at $\mathrm{pH}$ 6.8) and loaded onto a $12 \%$ acrylamide gel (Bio-Rad Laboratories, Hercules, CA, USA), and then transferred to a PVDF membrane (Immobilon-P, Millipore, Bedford, MA, USA) using mini Trans-Blot Electrophoretic transfer cell (Bio-Rad Laboratories, Hercules, CA, USA). Membranes were blocked with $5 \%$ non-fat milk and incubated overnight at $4{ }^{\circ} \mathrm{C}$ with the antibodies indicated in Table 1 , followed by a second incubation during $2 \mathrm{~h}$ at room temperature with an $\mathrm{ECL}^{\mathrm{TM}}$ Horseradish Peroxidase-linked whole secondary antibody (GE Healthcare UK Limited, Buckinghamshire, UK) at a 1:5000 dilution. Reactive bands were detected by chemiluminescence with the Amersham $^{\mathrm{TM}} \mathrm{ECL}^{\mathrm{TM}}$ Prime Western Blotting Detection Reagent (GE Healthcare UK Limited, Buckinghamshire, UK). Images were analyzed on a ChemiDoc station with Quantity one software (Bio-Rad Laboratories, Madrid, Spain). Data were calculated as the ratio between the optical densities of the specific protein band and the housekeeping protein GAPDH, and they were normalized as percentages over the control group for presentation.

LC/MS analysis for endocannabinoid levels. The amounts of endocannabinoids and related 
Table 1. List of antibodies used in Western blotting or immunohistochemical analyses (WB: Western blotting; IHC: immunohistochemistry)

\begin{tabular}{lllll}
\hline ANTIBODY & DILUTION (IHC) & DILUTION (WB) & CLASS & MANUFACTURER \\
\hline anti-CB 1 : Rb-Af380 & $1: 500$ & $1: 300$ & Polyclonal & Frontier Institute, Hokkaido, Japan \\
anti-FAAH:SC-26427 & $1: 200$ & $1: 200$ & Polyclonal & Santa Cruz Biotechnology, CA, USA \\
anti-calbindin D-28 K:AB1778 & $1: 250$ & $1: 500$ & Polyclonal & Millipore, Billerica, MA, USA \\
anti- ataxin-3: MAB5360 & & $1: 500$ & Polyclonal & Millipore, Billerica, MA, USA \\
anti-polyQ:MAB1574 & & $1: 500$ & Monoclonal & Millipore, Billerica, MA, USA \\
anti-GAPDH:G8795 & $1: 5000$ & Monoclonal & Sigma Chem., Madrid, Spain \\
anti-GFAP:Z0334 & $1: 500$ & & Polyclonal & DakoCytomation, Glostrup, Denmark \\
anti-Iba1:019-19741 & $1: 300$ & Polyclonal & Wako, Osaka, Japan \\
anti-ubiquitin:Z0458 & $1: 200$ & & Polyclonal & DakoCytomation, Glostrup, Denmark \\
\hline
\end{tabular}

$\mathrm{N}$-acylethanolamines and 2-acylglycerols were determined by liquid chromatography-atmospheric pressure chemical ionization-mass spectrometry (LC/MS; 1100 LC-MSD, SL model; Agilent Technologies Inc., Wilmington, DE, USA). The protocol used was described previously (Patel et al., 2003) with slight modifications. Tissue samples were weighed and placed into borosilicate glass tubes containing $2 \mathrm{ml}$ of acetonitrile with $84 \mathrm{pmol}$ of $\left[{ }^{2} \mathrm{H}_{8}\right] \mathrm{AEA}$ and $186 \mathrm{pmol}$ of $\left[{ }^{2} \mathrm{H}_{8}\right] 2-\mathrm{AG}$ (Cayman Chemical, Ann Arbor, MI, USA). Tissues were homogenized with a glass rod and sonicated for $60 \mathrm{~min}$. Samples were incubated overnight at $-20^{\circ} \mathrm{C}$ to precipitate proteins. Samples were centrifuged at $1500 \mathrm{~g}$ for $3 \mathrm{~min}$, and supernatants were removed to a new glass tube and evaporated to dryness under nitrogen. The samples were resuspended in methanol $(300 \mu \mathrm{l})$ to recapture any lipids adhering to the glass tube, and dried again. Finally, lipid extracts were suspended in $30 \mu \mathrm{l}$ of methanol, $5 \mu \mathrm{l}$ of which were used for the LC/MS analysis. Samples were separated on a reverse-phase C18 column (Kromasil, $250 \times 2 \mathrm{~mm}, 5-\mu \mathrm{m}$ diameter) using mobile phase $A$ (deionized water with $1 \mathrm{mM}$ ammonium acetate and $0.005 \%$ acetic acid) and mobile phase B (methanol with $1 \mathrm{mM}$ ammonium acetate, and $0.005 \%$ acetic acid). Samples were eluted at a flow rate of $300 \mu \mathrm{l} / \mathrm{min}$ by a linear gradient. The percentage of solvent B increased linearly from $85 \%$ to $100 \%$ in $25 \mathrm{~min}$ then held at $100 \%$ solvent B for 10 min. Over the next 10 min, solvent B decreased linearly from 100 to $85 \%$ and was held at $85 \%$ for an additional period of $10 \mathrm{~min}$. MS detection was carried out in the selected ion monitoring mode using $\mathrm{m} / \mathrm{z}$ values to detect $\left[{ }^{2} \mathrm{H}_{8}\right]$ AEA (m/z 356), AEA (m/z 348), $\left[{ }^{2} \mathrm{H}_{8}\right] 2-A G$ and 1(3)-AG (m/z 387), 2-AG and 1(3)-AG (m/z 379), PEA (m/z 299), OEA (m/z 326) and 2-OG and 1(3)-OG $(\mathrm{m} / \mathrm{z} 357)$. As 2-AG and 2-OG are usually observed as doublets because of isomerization to the 1,3 form during extraction (Patel et al., 2003), the area of both peaks were combined to yield total 2-AG or 2-OG. To calibrate the system, standard curves for the AEA, PEA, OEA, 2-AG and 2-OG (Cayman Chemical, Ann Arbor, MI, USA) were used. Each endocannabinoid concentration in the different samples was calculated by comparison with the corresponding deuterated internal standard: $\left[{ }^{2} \mathrm{H}_{8}\right] \mathrm{AEA}$ for calculating AEA, PEA and OEA levels, and $\left[{ }^{2} \mathrm{H}_{8}\right] 2-A G$ in the case of 2-AG and 2-OG. The amounts of endocannabinoids and related $\mathrm{N}$-acylethanolamines and 2-acylglycerols calculated were normalized to wet tissue weight and expressed as \% over the control group for presentation.

\section{Histological procedures}

Tissue slicing. Fixed brains were sliced with a cryostat to obtain sagittal sections ( $30 \mu \mathrm{m}$ thick), including the two areas under investigation, that were collected on gelatincoated slides. Sections were used for procedures of Nissl-staining or immunohistochemistry.

Niss/ staining. The frozen brain sagittal sections were incubated with a solution of methylene blue $0.1 \%$ for $5 \mathrm{~min}$ and washed with distilled water. The samples were dehydrated, sealed and coverslipped with nonaqueous mounting medium. A Leica DMRB microscope (Leica, Wetzlar, Germany) and a DFC300FX camera (Leica) were used for the observation and photography of the slides, respectively. For counting the number of Nissl-stained cells, high resolution photomicrographs were taken with the $20 x$ objective under the same conditions of light, brightness and contrast. Four images coming from at least three sections per animal were analyzed. The final value for each group is the mean for all animals included in the study. Data are expressed as percentage over the wild-type group.

Immunohistochemistry. Slices were preincubated for $20 \mathrm{~min}$ in $0.1 \mathrm{M}$ PBS with $0.1 \%$ Triton $\mathrm{X}-100, \mathrm{pH} 7.4$, and subjected to endogenous peroxidase blockade by incubation for $1 \mathrm{~h}$ at room temperature in peroxidase blocking solution (Dako Cytomation, Glostrup, Denmark). After incubation with the corresponding primary antibody (see details of the different antibodies used and their conditions in Table 1) in $0.1 \mathrm{M}$ PBS with $0.01 \%$ Triton $\mathrm{X}-100, \mathrm{pH} 7.4$, overnight at $4{ }^{\circ} \mathrm{C}$, sections were washed in $0.1 \mathrm{M}$ PBS and incubated for $2 \mathrm{~h}$ at room temperature with the appropriate biotin-conjugated anti-goat or anti-rabbit secondary antibodies (1:200; Vector Laboratories, Burlingame, CA, USA). Avidinbiotin complex (Vectastain ${ }^{\circledR}$ Elite ABC kit; Vector Laboratories, Burlingame, CA, USA) and a DAB substrate-chromogen system (Dako Cytomation, Glostrup, Denmark) were used to obtain a visible reaction product. Negative control sections were obtained using the same protocol with omission of the primary antibody. All sections for each immunohistochemical procedure were processed at the same time and under the same conditions. A Leica DMRB microscope and a Leica DFC300FX camera 
(Leica, Wetzlar, Germany) were used for slide observation and photography.

\section{Statistics}

Data were assessed by unpaired Student's $t$-test or twoway ANOVA for repeated measures followed by the Bonferroni test, as required, using the GraphPad software (version 5.0). The Long Rank method was used for the analysis of Kaplan-Meier curves.

\section{RESULTS}

\section{Characterization of the pathological phenotype in SCA-3 transgenic mice}

This study was initiated before the first report with the neurological and neuropathological characterization of these SCA-3 transgenic mice was published (SilvaFernandes et al., 2014), so we first characterized the mice with a threefold purpose: (i) to confirm that, in our hands, animals developed a pathological phenotype reminiscent of SCA-3; (ii) to establish the best stages in the disease progression during which to investigate the changes in the endocannabinoid signaling; and (iii) to determine the most-affected CNS structures in which this should be investigated. We found, using western blotting, expression of human ataxin-3 only in transgenic mice in contrast with the expression of mouse ataxin-3 in both wild-type and SCA-3 transgenic mice (Fig. 1A). We also confirmed by western blotting, using an anti-polyglutamine antibody, that polyQ expansions were only evident in SCA-3 transgenic mice (Fig. 1B). In agreement with the data published by Silva-Fernandes et al. (2014), this cohort of SCA-3 transgenic mice did not survive longer than 80 weeks after birth, an age at which all wild-type animals were alive (Fig. 1C). SCA-3 transgenic mice gained weight during the first 3 months of age but, starting at the age of 15 weeks after birth, they lost the capability to gain weight compared to wild-type animals (Fig. 1D). Later on, they exhibited weight loss that was noted first at the age of 39 weeks, but that prolonged up to the last age recorded ( 55 weeks of age), a time-point in which the weight of SCA-3 transgenic animals was a $65 \%$ of the wild-type weight (Fig. 1D). At the age of 56 weeks, SCA-3 transgenic mice were very debilitated showing, together with the weight loss, an excessive curvature of the spine called kyphosis, which was extremely marked at such age (Fig. 1J), although it was already visible at the age of 19 weeks (data not shown). The kyphosis could be also visualized with the help of the computer-aided tomography device at the age of 43 weeks (Fig. $1 \mathrm{~J}$ ) when both wild-type and SCA-3 transgenic mice were subjected to a PET analysis for quantifying glucose metabolism (see below). This excessive curvature of the spine has been observed in other SCA-3 murine models (Riess et al., 2008; Gould, 2012).

SCA-3 transgenic mice exhibited highly significant deficits that were initiated at the age of 11 weeks in the hanging wire test, useful to detect muscle weakness (Fig. 1E), and at the age of 15 weeks in the balance beam, useful to detect deficits in balance (Fig. 1F).
These deficits worsened progressively, in particular, the hanging wire deficits, up to the age of 31 weeks (Fig. $1 \mathrm{E}$ and $\mathrm{F}$ ), but the recording in these two tests had to be stopped at this age as transgenic mice were unable to perform at all. Deficits in rotarod performance, reflecting motor incoordination and also dystonia and muscle weakness, appeared at older ages, specifically at the age of 31 weeks but their intensity worsened up to the age of 55 weeks (Fig. 1G). One week later, animals were also examined for the presence of hindlimb clasping, which is frequently used as a marker of dystonia in a number of murine models of neurological disorders, including certain cerebellar ataxias (Chou et al., 2008). We found this response to be extremely frequent in our SCA-3 transgenic mice, as previously reported in other SCA-3 models (Gould, 2012), with values more than fourfold elevated (Fig. $1 \mathrm{H})$. The motor incoordination and imbalance detected in SCA-3 transgenic mice were also evident in the footprinting test, which reflects the animal gait, proving a completely disorganized performance (shorter strides and loss of balance) for these animals (Fig. 1I). Lastly, we also subjected our animals to in vivo positron emission tomography (PET) analysis for determining the regional glucose metabolism using 2-deoxy-2-[ $\left.{ }^{18} \mathrm{~F}\right]$ fluoro-D-glucose $\left(\left[{ }^{18} \mathrm{~F}\right] \mathrm{FDG}\right)$ at two ages within the disease progression: 21 and 43 weeks after birth. We did not find any alteration in the early symptomatic age (21 weeks), but we did find a large reduction in 43-week-old animals in the whole brain and also in those brain structures related to SCA-3 symptoms, e.g. cerebellum, brainstem, caudate-putamen, and also in other cortical and subcortical structures (Fig. 2). These results are in agreement with the data described with the same procedure in SCA-3 patients (Soong et al., 1997; Taniwaki et al., 1997).

Next, we attempted to find a neuropathological basis for the above behavioral abnormalities, by analyzing different biochemical markers that reflect neuronal malfunctioning, as well as by using histological procedures to identify neuronal losses or glial activation. We concentrated in two of the most-affected structures in SCA-3 in patients, i.e. cerebellum, brainstem (Murata et al., 1998; Taroni and DiDonato, 2004; Koeppen, 2005; Riess et al., 2008), and, in some cases, we included the analysis of the three selected ages representing the progression of the disease $(16,32$ and 56 weeks), or we focused exclusively in the advanced stage (56 weeks).

Most of the neuropathological analyses were concentrated in the changes in the calcium-dependent protein calbindin, which is frequently used as a marker for Purkinje cells in the cerebellum (Ishikawa et al., 1995). We did not find any changes in calbindin gene expression measured by qPCR in the three investigated ages, and this was corroborated by similar analysis using other neuronal markers such as neurons-specific enolase (NSE) (frequently used for neurons of the dentate nucleus; Nogami et al., 1998) and BDNF (Fig. 3A). In addition, we did find equivalent values for calbindin immunostaining in the Purkinje cell layer in 56-week-old 
A

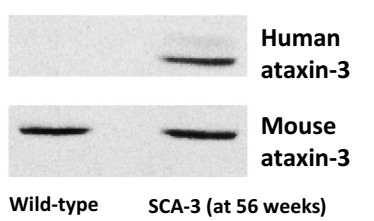

B

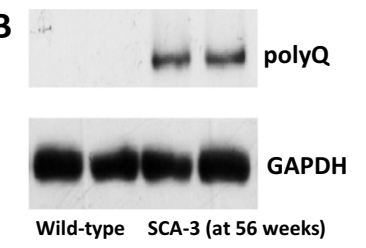

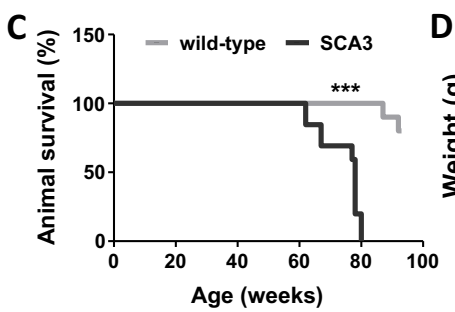

G

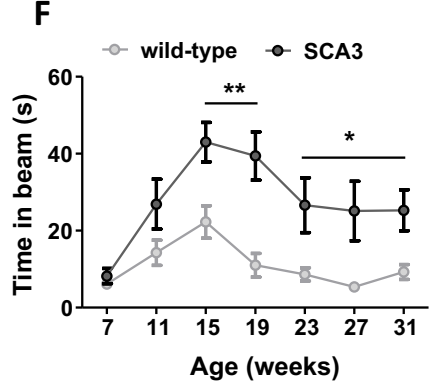

Wild-type (at 56 weeks)

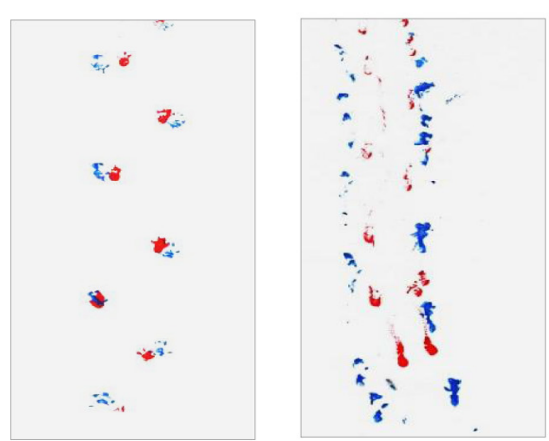

Wild-type (at 56 weeks) SCA-3 (at 56 weeks)
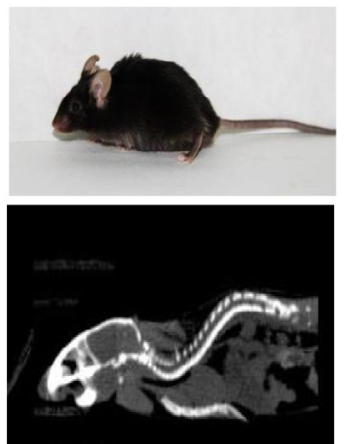

Wild-type (at 43 weeks)

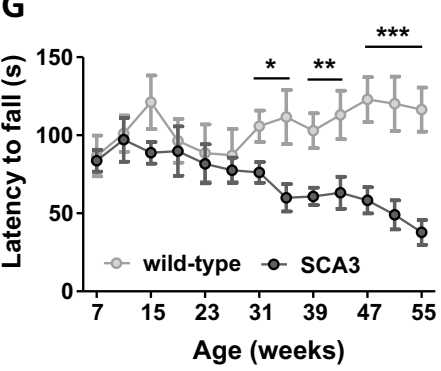

SCA-3 (at 56 weeks)

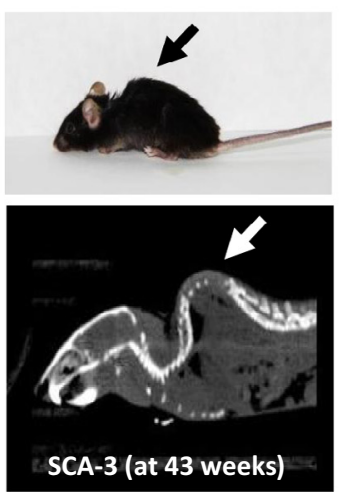

- wild-type -o- SCA3

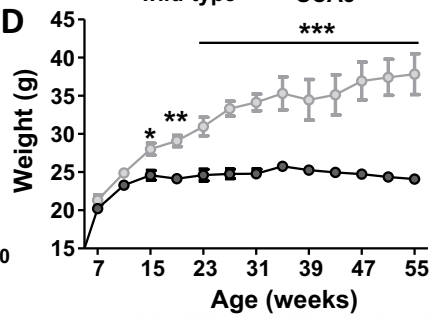

H

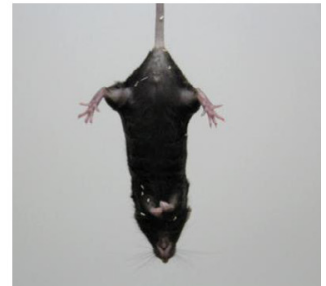

Wild-type (at 56 weeks)

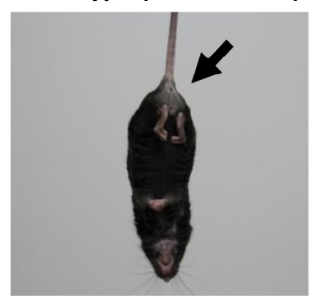

SCA-3 (at 56 weeks)
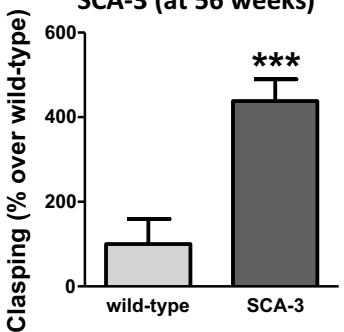

Fig. 1. Behavioral and biochemical characterization of SCA-3 transgenic mice compared to their wild-type genotype: Pane/s $A$ and $B$ : Western blot analysis for detecting the presence of human mutant ataxin-3 as well as polyQ expansions (only in SCA-3 transgenic mice), and mouse ataxin- 3 (in the two genotypes). Panel C: Kaplan-Meier curve for the analysis of animal survival in the two genotypes. Panels $D-G$ : Evolution of the animal weight and behavioral responses in the hanging-wire, balance beam and rotarod tests in the two genotypes at different ages from presymptomatic phases up to advanced stages ( 55 weeks of age, except for the hanging-wire and balance beam tests which SCA-3 transgenic mice were unable to perform at ages older than 31 weeks after birth). Panels $H$ and $\mathrm{J}$ : Evidence of clasping behavior, altered footprinting and kyphosis in SCA-3 transgenic mice compared to wild-type animals at an advanced stage in the disease progression (56 weeks after birth). Computer-aided tomography images of 43-week-old SCA-3 transgenic and wild-type animals taken during the PET analysis of these animals are also shown in panel $\mathrm{J}$ (bottom). In all cases, values are expressed as mean \pm SEM of more than six subjects per group. Data were assessed, as required, by Student's $t$-test or a two-way analysis of variance for repeated measures followed by the Bonferroni test. The Long Rank method was used for the analysis of Kaplan-Meier curves $\left(p<0.05,{ }^{* \star} p<0.01,{ }^{* \star *} p<0.005\right.$ versus wild-type animals).

SCA-3 transgenic mice compared to their wild-type animals (Fig. 3B), which is in agreement with previous data obtained in patients that indicated a relative preservation of these cells in SCA-3 (Gould, 2012). The same result was, in general, obtained when calbindin levels were analyzed by western blot in the whole cerebellum of both genotypes at 56 weeks after birth (Fig. 3C), although certain trend toward a decrease could be appreciated in SCA-3 transgenic mice (Fig. $3 \mathrm{C}$ ). This trend, seen when the whole cerebellum was analyzed, possibly derives from the reduction observed in calbindin immunostaining in the dentate nucleus (Fig. 3D), a cerebellar area notably affected in this SCA-3 transgenic model (Silva-Fernandes et al., 2014) and also in SCA-3 patients (Matilla-Dueñas, 2012; Seidel et al., 2016). The analysis of this nucleus with Nissl staining confirmed that the number of stained cells was significantly reduced, whereas surviving neurons showed a shrunken cell body, in 56-week-old SCA3 transgenic mice compared to wild-type animals (Fig. 3E). These data are in agreement with losses in the projecting neurons of the dentate nucleus as has been seen in patients (Evert et al., 2006). The loss of calbindin immunostaining in the dentate nucleus may also correspond to axons of Purkinje cells that project to such nucleus (Fig. 3D), and this could be related to the grumose degeneration typically observed in SCAs (Koeppen et al., 2013). As mentioned above, these differences were not noted in the cell bodies of Purkinje cells, when they were labeled with calbindin (Fig. 3B). We also tried to label Purkinje cells with ubiquitin, which 
mPET analysis in 21 week-old mice
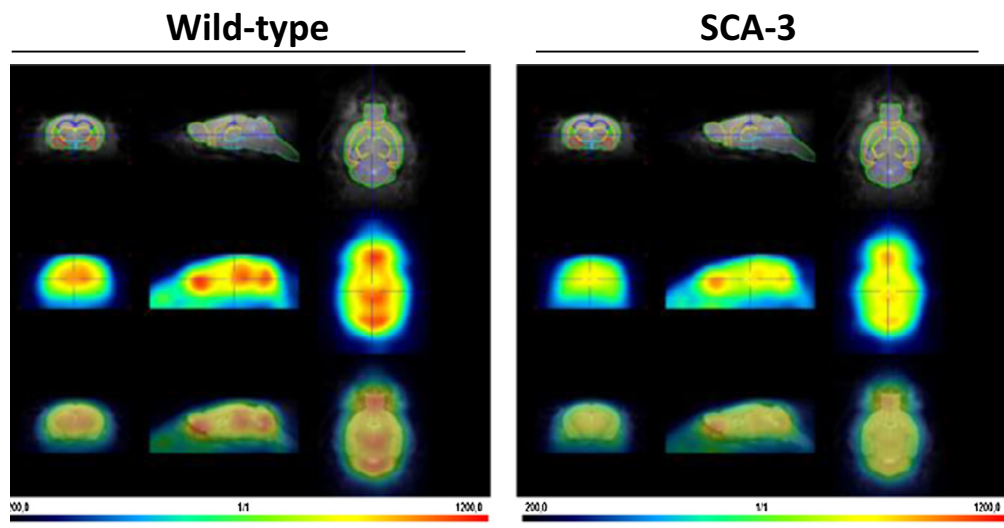

\section{mPET analysis in 43 week-old mice}

Wild-type

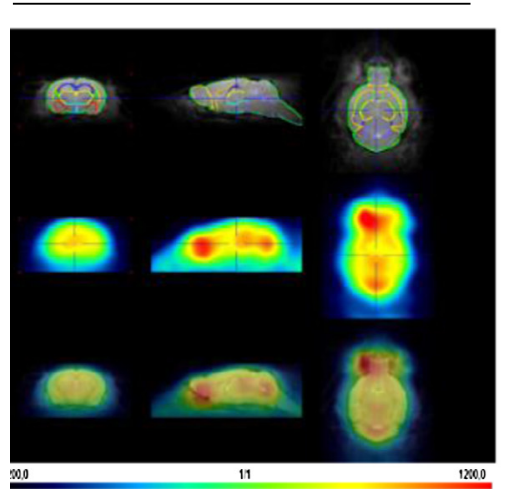

SCA-3

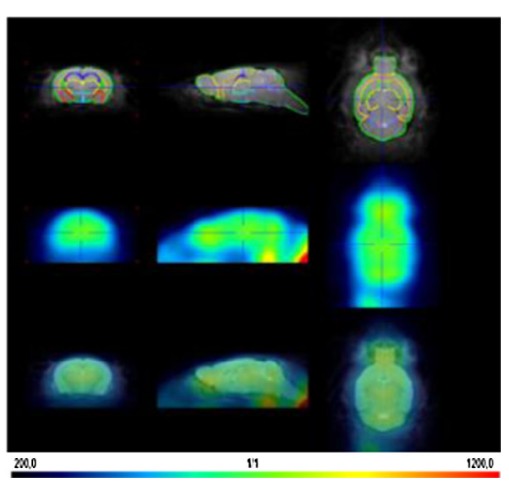

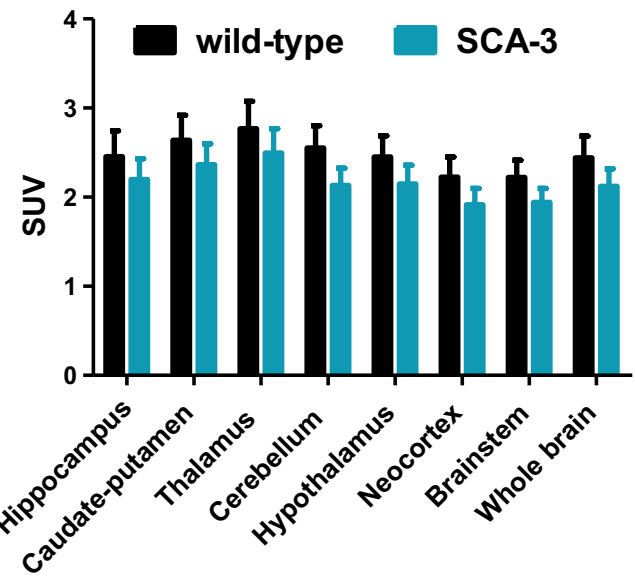
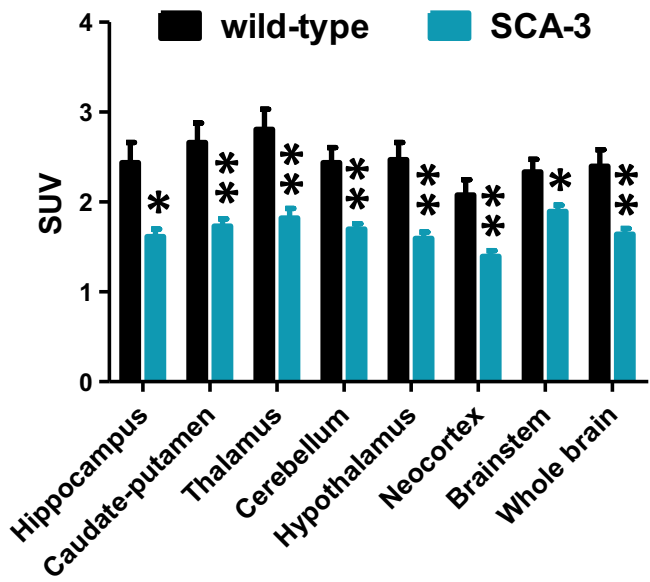

Fig. 2. In vivo imaging of the CNS of SCA-3 transgenic and wild-type mice: In vivo glucose metabolic rates measured by PET analysis in different CNS structures of SCA-3 transgenic and wild-type mice at two ages during the disease progression (21 and 43 weeks after birth). Values correspond to standard uptake value (SUV) and are expressed as mean \pm SEM of 5-6 subjects per group and age. Data were assessed by Student's $t$-test $\left({ }^{*} p<0.05,{ }^{* *} p<0.01\right)$.

is a marker of intracellular inclusions derived from mutant ataxin-3 aggregation, but we were unable to detect such inclusions in these cells (data not shown), which, however, were evident in brainstem nuclei (see below). This absence of ubiquitin-positive inclusions in the Purkinje cells has been also described in other studies (Taroni and DiDonato, 2004). On the other hand, we were unable to detect any evidence of glial activation in the cerebellum of SCA-3 transgenic mice compared to wild-type animals, as revealed the similar values of gene expression seen for the proinflammatory cytokines interleukin-1 $\beta$ (IL-1 $\beta$ ) and tumor necrosis factor- $\alpha(\mathrm{TNF}-\alpha)$ and for the glial glutamate-aspartate transporter (GLAST) and glutamate transporter-1 (GLT-1) at the three investigated ages (Fig. 4A). This absence of gliosis was corroborated by immunostaining with the microglial marker lba-1, which proved similar number of cells and immunoreactivity levels in the cerebellar cortex and dentate nucleus of 56-week-old SCA-3 transgenic and wild-type mice (Fig. 4B), a result also seen at earlier ages, 16 and 32 weeks after birth (data not shown). We also paid attention to the microglial morphology, which also reflects microglial activation, and, whereas there were no differ- ences at 16 and 32 weeks, we could appreciate some changes at 56 weeks restricted to the dentate nucleus, the only cerebellar area showing neuronal losses in SCA-3 transgenic mice. These changes consisted in a relative increase in the cell body size and a shortening in their processes when compared to wild-type animals (Fig. 4B). We also analyzed these structures with GFAP immunostaining but we did not find any differences between SCA-3 transgenic and wild-type mice (data not shown). This absence of gliosis in SCA-3 is not rare as it has been previously found in other studies also working with SCA-3 tissues (Rüb et al., 2013).

In addition, we were unable to reveal any significant differences in calbindin and NSE gene expression in the brainstem of SCA-3 transgenic and wild-type mice at the three investigated disease stages, always when the whole brainstem was used for qPCR analysis (Fig. 5A). This also happened with the analysis of BDNF gene expression (Fig. 5A), despite reductions in the expression of this neurotrophin have been found in this structure in cellular models and post-mortem tissues of SCA-3 patients (Evert et al., 2003). We also performed Nissl staining of brainstem slices and found that the 

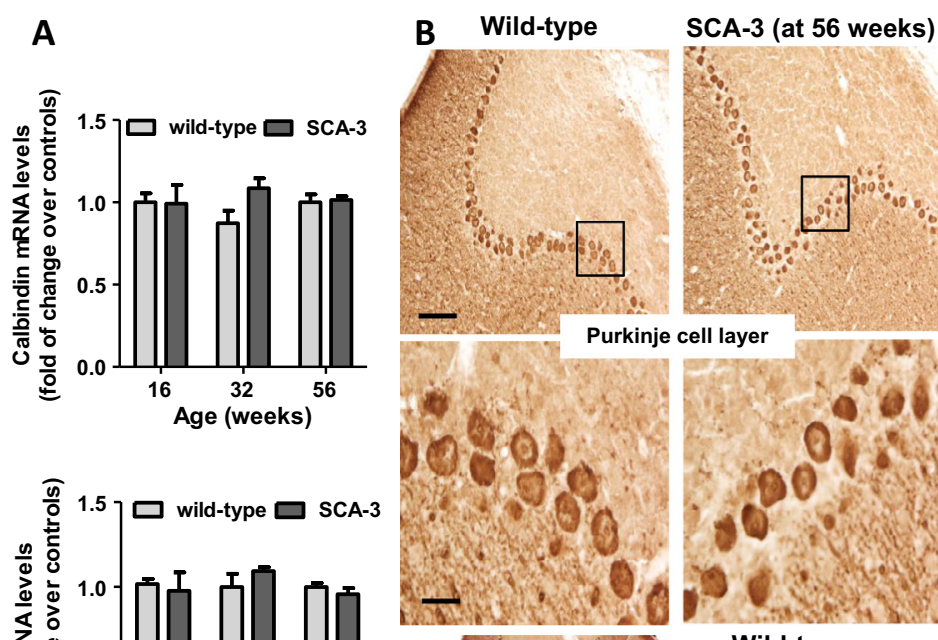

\section{C}
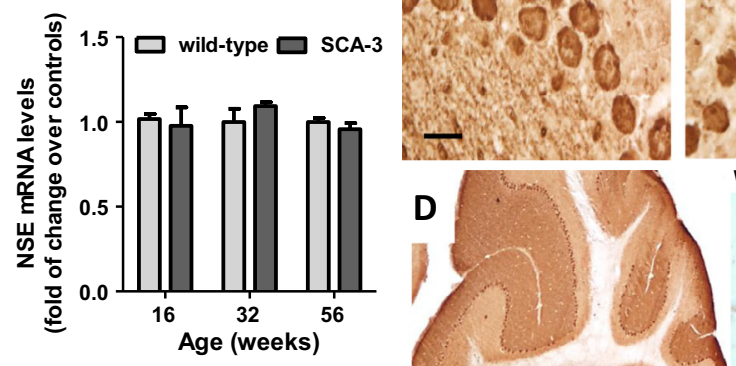

Wild-type


Fig. 3. Histological and biochemical analysis of neuronal injury in the cerebellum of SCA-3 transgenic and wild-type mice: Panel A: qPCR analysis of calbindin, neuron-specific enolase, and BDNF in the cerebellum of SCA-3 transgenic and wild-type mice at different ages in disease progression. Panels $B$ and D: Immunostaining for calbindin as a neuronal marker in the Purkinje cell layer (bar $=200 \mu \mathrm{m}$ and $50 \mu \mathrm{m}$, respectively), including quantification, and the dentate nucleus (bar $=800 \mu \mathrm{m}, 50 \mu \mathrm{m}$ and $20 \mu \mathrm{m}$, respectively) of SCA-3 transgenic and wild-type mice at 56 weeks after birth. Arrows indicate the location of calbindin-positive terminals in the dentate nucleus reflecting the low immunoreactivity seen in SCA-3 transgenic mice. Panel C: Western blot quantification (with a representative blot) of calbindin in the whole cerebellum of SCA-3 transgenic and wild-type mice at 56 weeks after birth. Panel E: Nissl staining and quantification in the dentate nucleus of SCA-3 transgenic and wild-type mice at 56 weeks after birth (bar $=25 \mu \mathrm{m}$ ). Arrows indicate the presence of shrunken cell bodies in SCA-3 transgenic animals. In all cases, values are expressed as mean \pm SEM of more than six subjects per group. Data were assessed by Student's $t$-test $\left({ }^{*} p<0.05\right.$ versus wild-type animals).

number of Nissl-stained cells in the pontine nuclei, which is a highly-vulnerable brainstem structure in SCA-3 (Koeppen, 2005; Koeppen et al., 2013; Silva-Fernandes et al., 2014), was significantly reduced in 56-week-old SCA-3 transgenic mice when compared to wild-type, with notable changes in the morphology of remaining Nisslstained cells (Fig. 5B). This did not occur in another relevant brainstem area such as the inferior olivary nucleus (Fig. 5B). As mentioned above, we were able to detect in this area positive ubiquitin immunostaining, which was found in inclusions located in neurons of the pontine nuclei and inferior olivary nucleus of 56-week-old SCA-3 transgenic mice (Fig. 5C), but not in wild-type tissues (Silva-Fernandes et al., 2014). Such ubiquitin-positive inclusions have been also found in patients and in other models of SCA-3 (Paulson et al., 1997). The analysis of glial activation in the whole brainstem revealed a statisti- cally significant elevation in gene expression for TNF- $\alpha$ and a trend toward an increase in IL-1 $\beta$ in SCA-3 transgenic mice but only at 56 weeks (Fig. 6A), a response also found in SCA-3 patients (Evert et al., 2003, 2006). This elevation of proinflammatory cytokines, which mainly derive from microglial cells, was not associated with an elevated immunoreactivity for the microglial marker Iba1 in the pontine nuclei of SCA-3 transgenic mice neither at 56 weeks (Fig. 6B) nor at 16 and 32 weeks after birth (data not shown). However, as in the cerebellum, we paid attention to the microglial morphology and again, whereas there was no differences at 16 and 32 weeks, we could appreciate an apparent increase in the cell body size and a shortening in the processes of microglial cells in the pontine nuclei of SCA-3 transgenic mice when compared to wild-type animals at 56 weeks (Fig. 6B). We also measured glutamate transporters which, due to their 


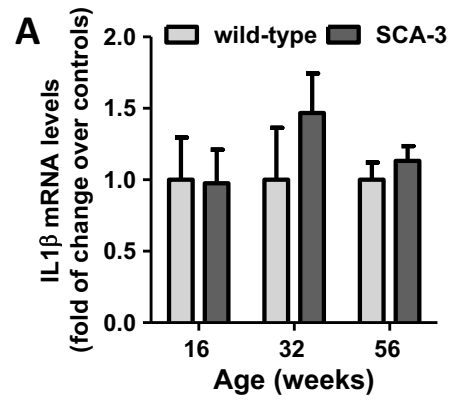

B
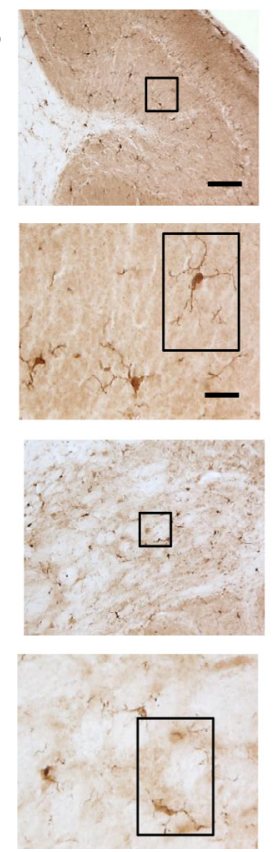

Wild-type
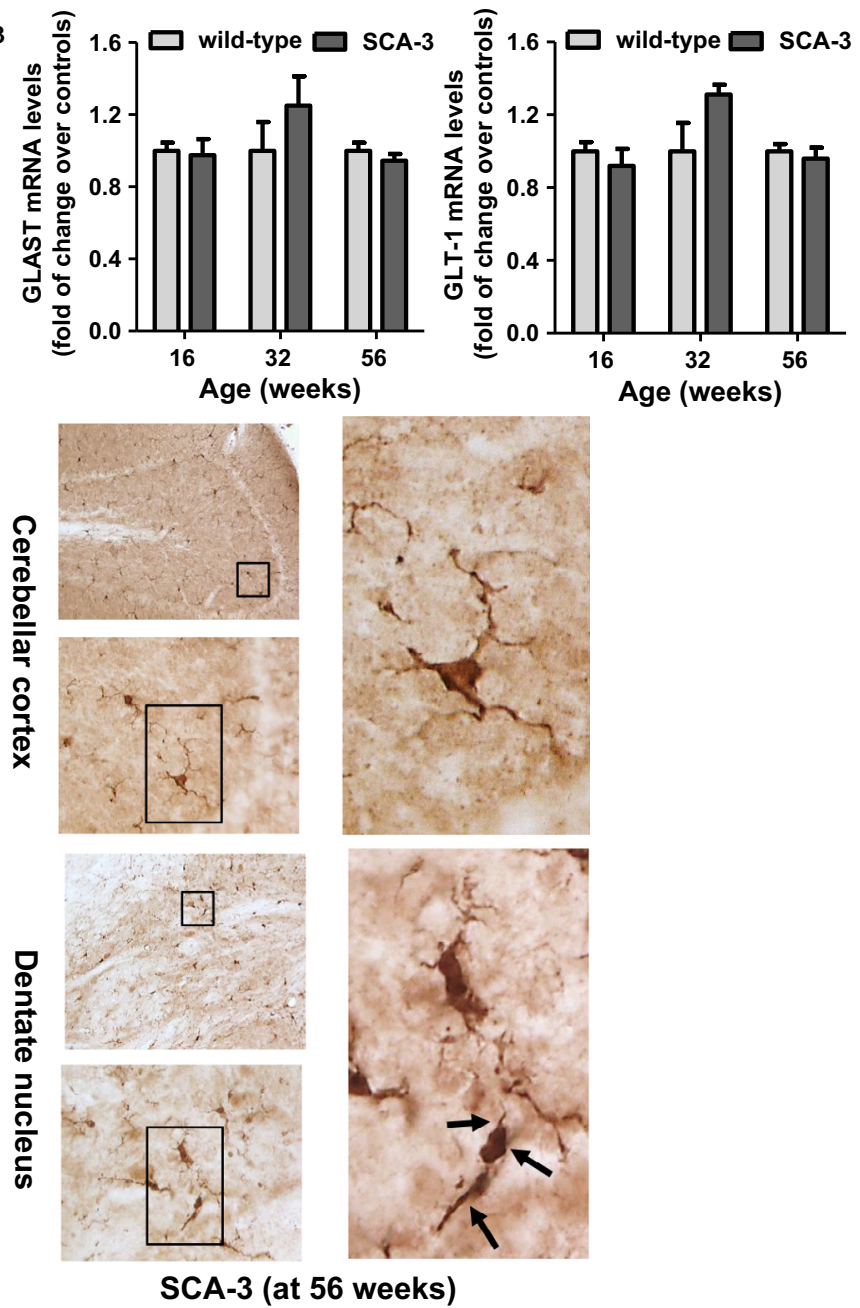

Fig. 4. Histological and biochemical analysis of glial activation in the cerebellum of SCA-3 transgenic and wild-type mice: Panel A: qPCR analysis of the proinflammatory cytokines IL-1 $\beta$ and TNF- $\alpha$, and the glial glutamate transporters GLAST and GLT- 1 , in the cerebellum of SCA-3 transgenic and wild-type mice at different ages in disease progression. Panel B: Immunostaining for Iba-1 as a microglial marker in the cerebellar cortex and the dentate nucleus of SCA-3 transgenic and wild-type mice at 56 weeks after birth (bar $=200 \mu \mathrm{m}, 50 \mu \mathrm{m}$ and $10 \mu \mathrm{m}$, respectively). Arrows indicate the presence of microglial cells with altered morphology (increased cell body and shorter processes) in the dentate nucleus of SCA-3 transgenic mice. In all cases, values are expressed as mean \pm SEM of more than six subjects per group. Data were assessed by Student's $t$-test.

preferential location in astroglial cells, may be used as an index of the activity of these cells. We found the gene expression for GLT-1 to be reduced at 32 and 56 weeks, with GLAST reduced only at 56 weeks (Fig. 6A). However, these responses were not associated with changes in the immunostaining for the astrocyte marker GFAP in brainstem structures of SCA-3 transgenic mice compared to wild-type animals (data not shown).

\section{Analysis of the endocannabinoid signaling system in the cerebellum of SCA-3 transgenic mice}

The main objective of this study was to determine whether the endocannabinoid signaling system becomes dysregulated in the most-affected CNS structures of SCA-3 transgenic mice, so that this dysregulation may be pharmacologically corrected with benefits for disease symptoms and progression, or, alternatively, the potential changes may be enhanced in the case they represent an adaptive response aimed at restoring cell and tissue homeostasis as found in other neurodegenerative disorders (Di Marzo et al., 2015). We concentrated in six key endocannabinoid elements, the $\mathrm{CB}_{1}$ and $\mathrm{CB}_{2}$ receptors, the two synthesizing enzymes, $\mathrm{N}$-arachidonoylphosphatidylethanolamine-phospholipase $D$ (NAPE-PLD) and diacylglycerol lipase (DAGL), and the two hydrolyzing enzymes, FAAH and MAGL, which were first analyzed by qPCR in the three stages stated before, and, upon the expectation of significant changes, we completed the analysis using western blot and immunostaining. The changes only occurred for the $\mathrm{CB}_{1}$ receptor and the FAAH enzyme. We also carried out analysis of endocannabinoids and related signaling lipids at the three investigated stages.

The first CNS structure investigated was the cerebellum. We first analyzed the expression of the $\mathrm{CB}_{1}$ receptor by qPCR, but we did not detect any difference between SCA-3 transgenic and wild-type mice at the three investigated stages (Fig. 7A). However, the Western blot analysis of this structure at the age of 

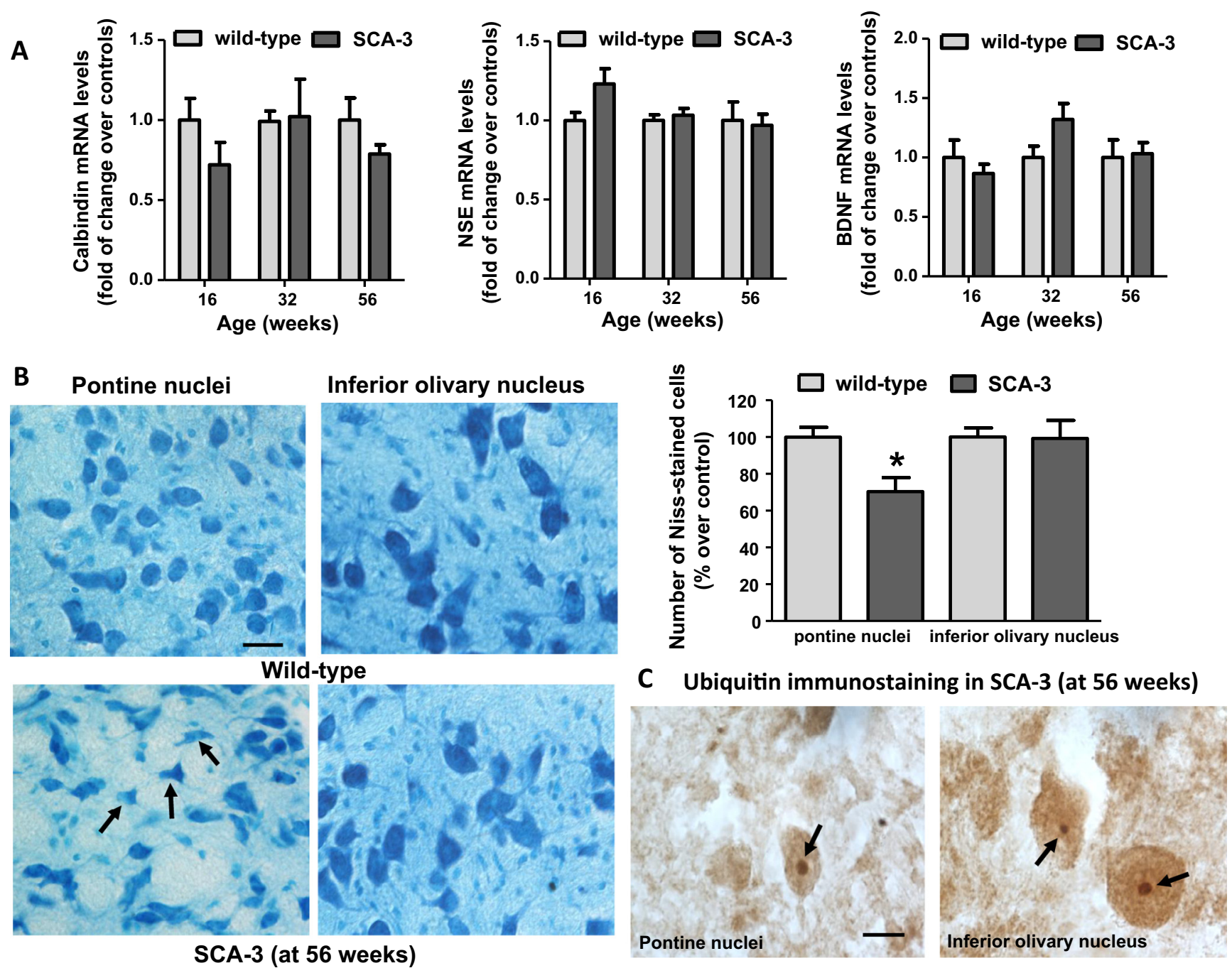

Fig. 5. Histological and biochemical analysis of neuronal injury in the brainstem of SCA-3 transgenic and wild-type mice: Panel A: qPCR analysis of calbindin, neuron-specific enolase, and BDNF in the brainstem of SCA-3 transgenic and wild-type mice at different ages in disease progression. Panel B: Nissl staining and quantification in the pontine nuclei and inferior olivary nucleus of SCA-3 transgenic and wild-type mice at 56 weeks after birth $(\mathrm{bar}=25 \mu \mathrm{m})$. Arrows indicate the presence of shrunken cell bodies in SCA-3 transgenic mice. Pane/ C: Immunostaining for ubiquitin (indicated by arrows) in the pontine nuclei and inferior olivary nucleus of SCA-3 transgenic mice at 56 weeks after birth (bar $=20 \mu \mathrm{m}$ ). In all cases, values are expressed as mean \pm SEM of more than six subjects per group. Data were assessed by Student's $t$-test $\left({ }^{*} \mathrm{p}<0.05\right.$ versus wild-type animals).

56 weeks revealed a significant increase in $\mathrm{CB}_{1}$ receptor levels (Fig. 7B), which presumably reflected the increase in $\mathrm{CB}_{1}$ receptor immunostaining seen in the cerebellar cortex and, in particular, the Purkinje cell layer at this stage (Fig. 7C), but not at earlier phases (data not shown). The increase in the Purkinje cell layer was most visible in the so-called pinceau formations which correspond to the basket cell terminals contacting the Purkinje cells (Suárez et al., 2008) (Fig. 7C). By contrast, we did not see a similar increase in $\mathrm{CB}_{1}$ receptor immunostaining in the granular layer or in the dentate nucleus (in this nucleus, the immunoreactivity was seen in projecting neurons and in fibers surrounding the cell bodies of such projecting neurons) in 56-week-old SCA3 transgenic mice (Fig. $7 \mathrm{C}$ ) or in earlier stages (data not shown). In fact, $\mathrm{CB}_{1}$ receptor immunoreactivity in the dentate nucleus appeared to be lower in SCA-3 transgenic mice, presumably due to the neuronal losses seen in this nucleus and discussed before.

Next, we measured FAAH enzyme and we detected an increase in its gene expression in SCA-3 transgenic mice at 16 weeks but not at older ages (Fig. 8A), which was paralleled by trends toward an increase in FAAH protein levels at 16 and 32 weeks after birth (Fig. 8B). Immunostaining for this enzyme in the Purkinje cell layer revealed the presence of FAAH in the Purkinje cells, as happened in the human samples (Rodríguez-Cueto et al., 2014b), but, also as happened in the samples from SCA patients (Rodríguez-Cueto et al., 2014b), the staining pattern in SCA-3 transgenic mice was different when compared to wild-type animals. In these animals, the immunoreactivity was located in the periphery of the cell body as described in previous studies (Romero et al., 2002), whereas it occupied the whole-cell body and was 

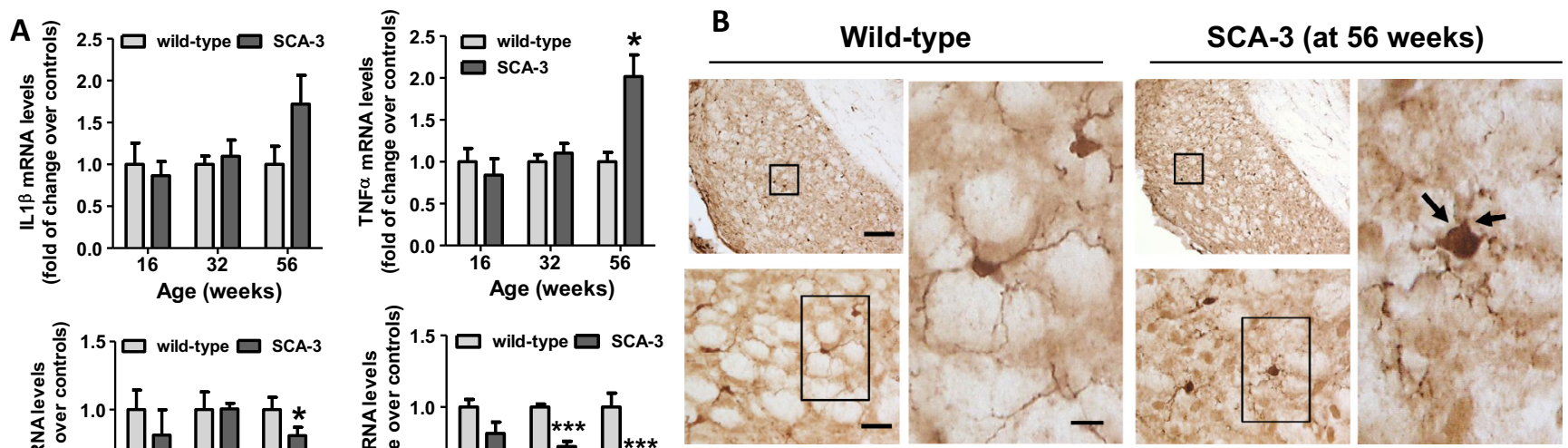

Pontine nuclei
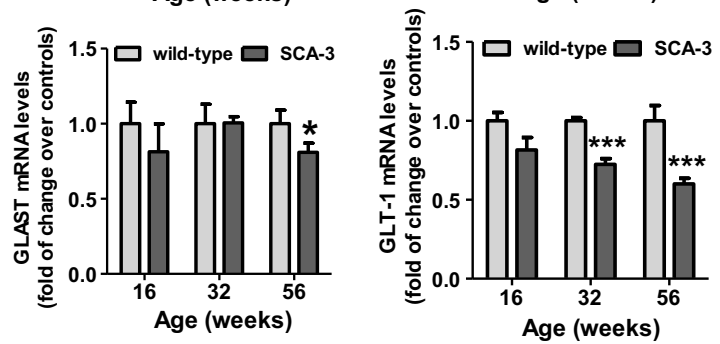

Fig. 6. Histological and biochemical analysis of glial activation in the brainstem of SCA-3 transgenic and wild-type mice: Panel A: qPCR analysis of the proinflammatory cytokines IL- $1 \beta$ and TNF- $\alpha$, and the glial glutamate transporters GLAST and GLT-1, in the brainstem of SCA- 3 transgenic and wild-type mice at different ages in disease progression. Panel B: Immunostaining for Iba-1 as a microglial marker in the pontine nuclei of SCA-3 transgenic and wild-type mice at 56 weeks after birth (bar $=200 \mu \mathrm{m}, 50 \mu \mathrm{m}$ and $20 \mu \mathrm{m}$, respectively). Arrows indicate the presence of microglial cells with altered morphology (increased cell body and shorter processes) in the pontine nuclei of SCA-3 transgenic mice. In all cases, values are expressed as mean \pm SEM of more than six subjects per group. Data were assessed by Student's $t$-test $\left({ }^{*} p<0.05,{ }^{* *} p<0.01,{ }^{* * *} p<0.005\right.$ versus wild-type animals).

more intense in the case of SCA-3 transgenic mice, and this was strongly evident at 16 and 32 weeks, but to a lesser extent at 56 weeks (Fig. $8 \mathrm{C}$ ). Such response also occurred in other cerebellar areas such as the white matter (Fig. 8D), but not in the dentate nucleus (data not shown). We also monitored the changes in other endocannabinoid genes, e.g. $\mathrm{CB}_{2}$ receptor, NAPE-PLD, DAGL and MAGL, along the three investigated stages, but we did not detect any difference between SCA-3 transgenic and wild-type mice (Fig. 9A-D). The lack of changes in $\mathrm{CB}_{2}$ receptors was in agreement with the absence of an important reactive gliosis, hence we discarded to further explore this receptor using immunostaining procedures. We also measured the levels of anandamide and 2-arachidonoylglycerol (2-AG), as well as their related signaling lipids palmitoylethanolamide (PEA), oleylethanolamide (OEA) and 2-oleylglycerol (2-OG), but they were similar in SCA-3 transgenic and wild-type mice in the three investigated disease stages (Fig. 9E-I).

\section{Analysis of the endocannabinoid signaling system in the brainstem of SCA-3 transgenic mice}

We also analyzed gene expression for the $\mathrm{CB}_{1}$ receptor in the whole brainstem, but we did not find any differences in the three stages investigated (Fig. 10A), which correlated with equivalent immunoreactivity for this receptor in the pontine nuclei also at the three ages investigated (Fig. 10B). In this nucleus, the immunoreactivity was detected both in cell bodies and fibers, as previously described (Cristino et al., 2006; Suárez et al., 2008).

Again, we next concentrated in FAAH enzyme whose gene expression in the whole brainstem did not vary along the disease progression (Fig. 10C). However, FAAH levels measured by Western blotting tended toward an increase at 16 weeks which reached statistical significance at 32 weeks in SCA-3 transgenic mice, although the differences disappeared at the advanced stage (56 weeks) (Fig. 10D). These differences were also evident using FAAH immunostaining, with immunoreactivity located in fibers and cell bodies that appeared to be much more marked in SCA-3 transgenic mice (Fig. 10E). This happened in different areas of the brainstem and it was particularly evident in the early and intermediate phases of the disease, with the pontine nuclei as the most relevant structure (Fig. 10E). We also measured the expression of other endocannabinoid genes, e.g. $\mathrm{CB}_{2}$ receptor, NAPE-PLD, DAGL and $M A G L$, along the three investigated stages, but again we did not detect any difference between SCA-3 transgenic and wild-type mice despite certain trends toward an increase seen for MAGL enzyme at 32 and 56 weeks (Fig. 11A-D). Lastly, we measured the levels of endocannabinoids, and related $\mathrm{N}$-acylethanolamines and 2-acylglycerols, and, in this case, we did find reductions in anandamide levels at 32 weeks (Fig. 11E), and in OEA levels at 16 and 32 weeks, and a trend toward a decrease at 56 weeks (Fig. 11H), which correlates well with the increase in FAAH enzyme indicated before (Fig. 10D-E). No changes were seen in brainstem levels of 2-AG (Fig. 11F), PEA (Fig. 11G) and 2-OG (Fig. 11I).

\section{DISCUSSION}

The data published by Silva-Fernandes et al. (2014), together with the additional neurological and neuropathological characterization carried out here in their SCA-3 transgenic mice, provide a solid evidence to consider this mouse model as a useful tool to investigate this human pathology. These mice exhibit a relatively slow disease progression, as in humans, living for more than 
A
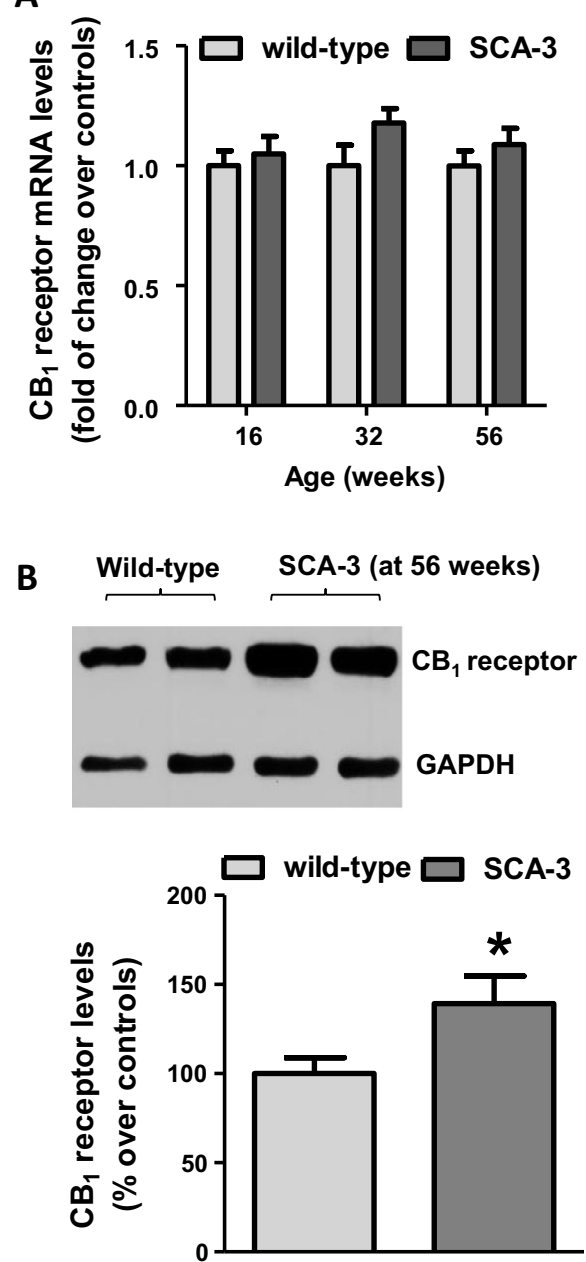

C
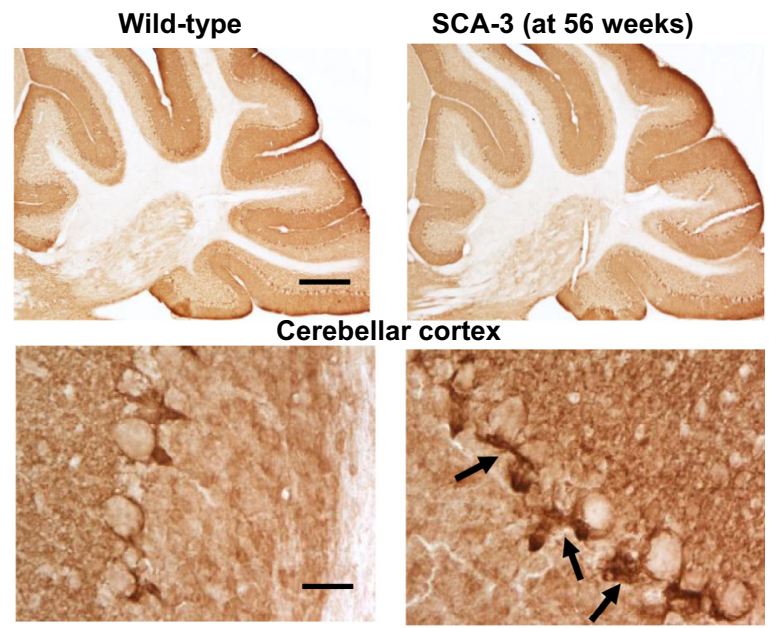

Purkinje cell layer

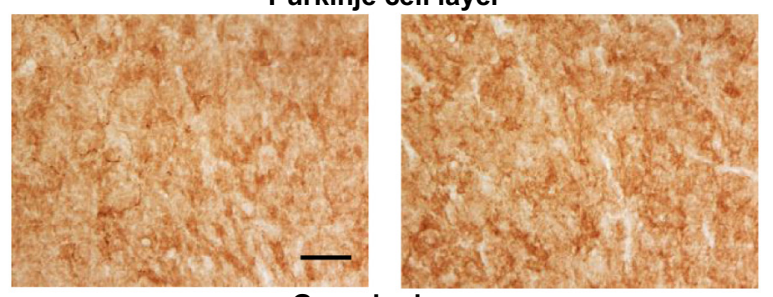

Granular layer

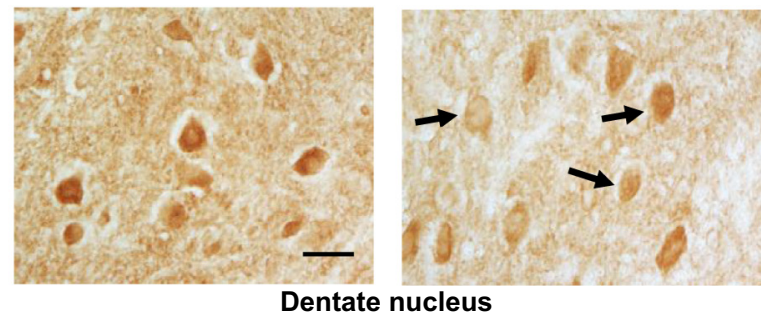

Fig. 7. Histological and biochemical analysis of the $\mathrm{CB}_{1}$ receptor in the cerebellum of SCA-3 transgenic and wild-type mice: Panel $A$ : $\mathrm{qPCR}$ analysis of the $\mathrm{CB}_{1}$ receptor in the cerebellum of SCA-3 transgenic and wild-type mice at different ages in disease progression. Panel $B$ : Western blot quantification (with a representative blot) of the $\mathrm{CB}_{1}$ receptor in the cerebellum of SCA-3 transgenic and wild-type mice at 56 weeks after birth. Panel $C$ : Immunostaining for the $\mathrm{CB}_{1}$ receptor in the cerebellar cortex $(\mathrm{bar}=800 \mu \mathrm{m})$, the Purkinje cell layer $(\mathrm{bar}=50 \mu \mathrm{m})$, the granular layer $(\mathrm{bar}=50 \mu \mathrm{m})$ and the dentate nucleus $(\mathrm{bar}=50 \mu \mathrm{m})$ of SCA-3 transgenic and wild-type mice at 56 weeks after birth. Arrows indicate the immunolabeling in pinceau formations (elevated immunoreactivity) and also in cell bodies of projecting neurons from the dentate nucleus (reduced immunoreactivity) in SCA-3 transgenic mice. In all cases, values are expressed as mean \pm SEM of more than six subjects per group. Data were assessed by Student's $t$-test $\left({ }^{*} p<0.05\right.$ versus wild-type animals).

one year. During this time, they exhibit a broad-spectrum of motor anomalies comparable to the clinical symptoms found in patients, which are the consequence of selective degeneration in neurons located in the cerebellum (dentate nucleus) and brainstem (pontine nuclei), which are all also affected in the human pathology (Koeppen, 2005; Matilla-Dueñas, 2012; Koeppen et al., 2013; Seidel et al., 2016). Also as found in humans, neurodegeneration does not appear to be associated with very marked glial activation and inflammatory events (Rüb et al., 2013). Nevertheless, there is an early alteration of glial glutamate transporters, which relates the degenerative process to excitotoxicity in the brainstem, but not in the cerebellum. This has been also found in other SCA3 models (Chou et al., 2008) and has been claimed by some authors as the basis for understanding the extension of neurodegeneration in SCA-3 to extracerebellar structures (Seidel et al., 2012). All this evidence support that this can be a useful model for the study of SCA-3 progression, including the contribution of the endocannabinoid signaling system to this progression, the objective pursued in this study, as well as for future preclinical studies with potential neuroprotective compounds, including also those acting at the different endocannabinoid targets.

Our study addressed for the first time the changes in the endocannabinoid signaling in the CNS of a murine model of SCA-3. As we have already mentioned, this is a necessary step in the development of a cannabinoid-based therapy for delaying the progression of the SCA-3-like pathological phenotype. Our idea was to investigate whether the endocannabinoid signaling becomes dysregulated in key CNS structures in these mice, and we confirmed that this is the case, as our findings are consistent with: (i) an elevated $\mathrm{CB}_{1}$ receptor signaling in the Purkinje cell layer, and the opposite in the dentate nucleus, in the cerebellum; and 

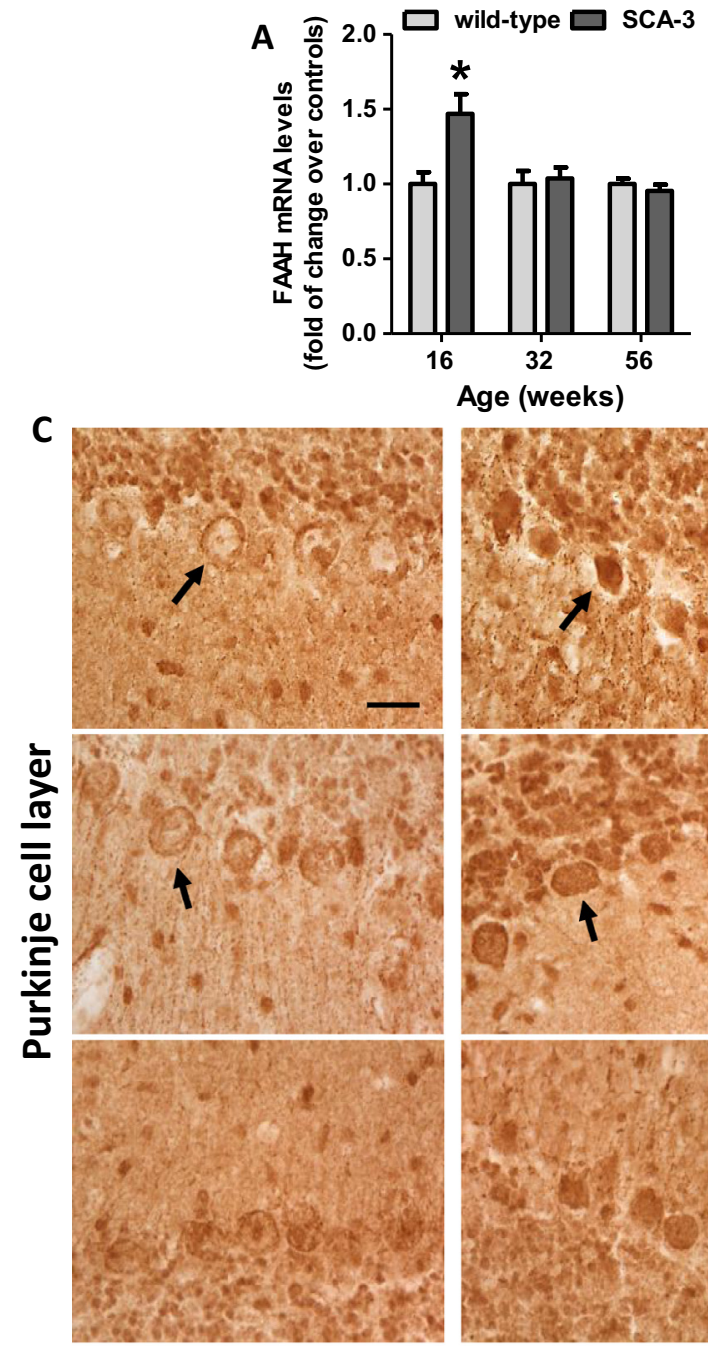

Wild-type
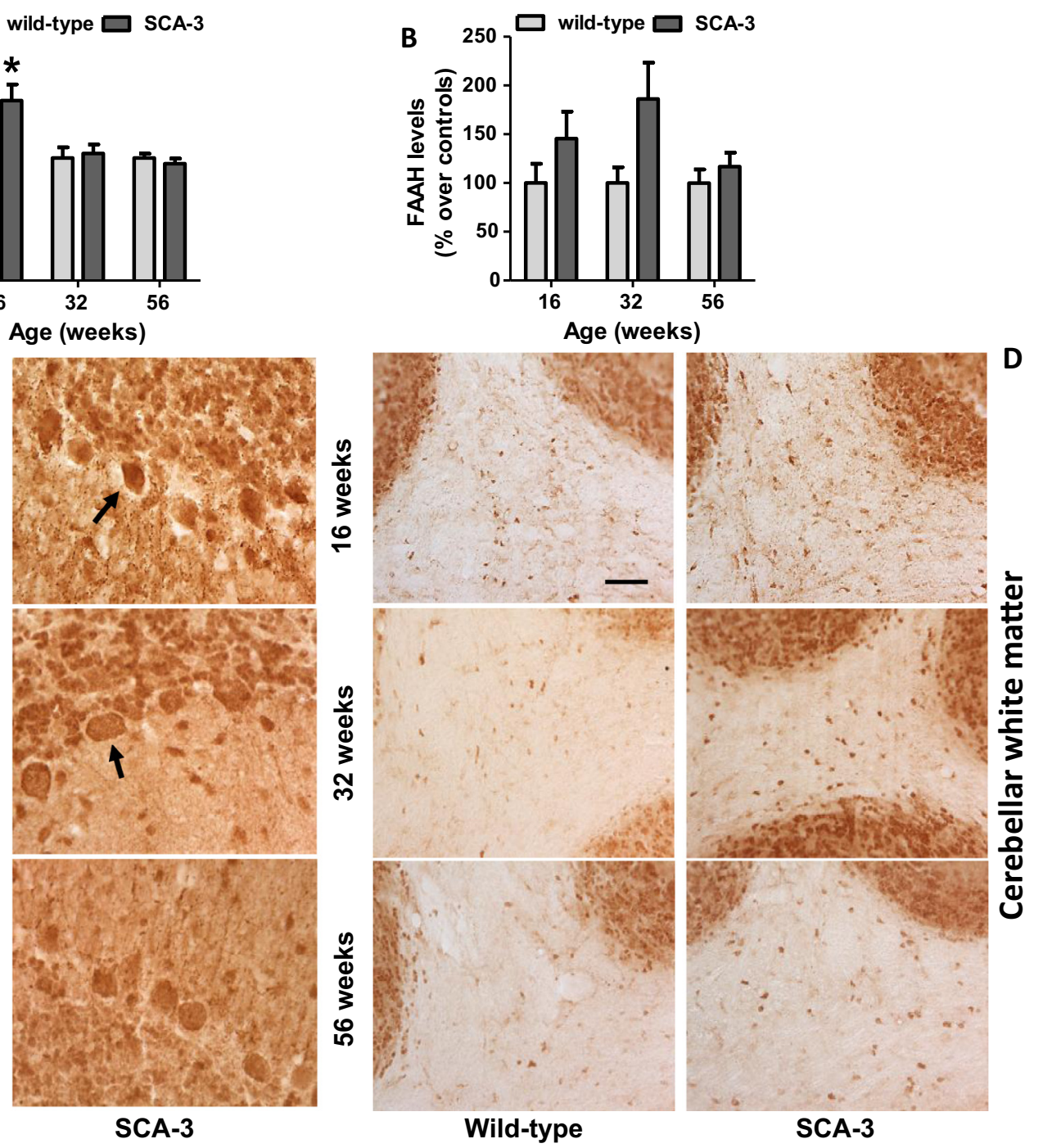

Fig. 8. Histological and biochemical analysis of the FAAH enzyme in the cerebellum of SCA-3 transgenic and wild-type mice: $P$ anels $A$ and $B$ : qPCR analysis and Western blot quantification of the FAAH enzyme in the cerebellum of SCA-3 transgenic and wild-type mice at different ages in disease progression. Panels $C$ and $D$ : Immunostaining for the FAAH enzyme in the Purkinje cell layer (C) and the cerebellar white matter (D) of SCA-3 transgenic and wild-type mice at different ages in disease progression (bar $=50 \mu \mathrm{m}$ for the Purkinje cell layer; bar $=100 \mu \mathrm{m}$ for the cerebellar white matter). Arrows indicate the differences in subcellular location of FAAH immunolabeling in Purkinje neurons of SCA-3 transgenic mice (located in the whole cell) compared to wild-type animals (located peripherally). In all cases, values are expressed as mean \pm SEM of more than six subjects per group. Data were assessed by Student's $t$-test $\left({ }^{*} p<0.05\right.$ versus wild-type animals).

(ii) an elevated FAAH-mediated degradation of endocannabinoids in the pontine nuclei of the brainstem. The occurrence of such dysregulated endocannabinoid signals are clearly dependent on cellular context, as they are not similar in the two structures investigated, and they can have some important consequences which will be addressed with more detail below.

First, endocannabinoid dysregulation may contribute to specific aspects of the pathogenesis, for example, loss of $\mathrm{CB}_{1}$ receptors may be related to excitotoxicity, given the role of this receptor in controlling glutamate homeostasis (Fernández-Ruiz et al., 2015), then facilitating neuronal losses. This may be the case of $\mathrm{CB}_{1}$ receptors in two key cerebellar areas: the Purkinje cell layer and the dentate nucleus. Our data indicate that $\mathrm{CB}_{1}$ receptors are preserved, and even elevated, in the Purkinje cell layer, which correlated with no losses of Purkinje cells and other neuronal subpopulations, whereas cell death was evident in neurons of the dentate nucleus in parallel to an apparent reduction in $\mathrm{CB}_{1}$ receptors in these neurons and also in terminals contacting such neurons. Interesting implications also derive from our observations concerning $\mathrm{FAAH}$, as we detected an elevation of this enzyme in certain brainstem nuclei in parallel to reduced levels of endocannabinoids, which may possibly diminish the capability of these signaling lipids to exert their protective role on cellular homeostasis, then facilitating the neuronal losses found in some structures such as the pontine nuclei.

Second, the changes in the endocannabinoid signaling may be also associated with the appearance of specific neurological symptoms in SCA-3 transgenic 

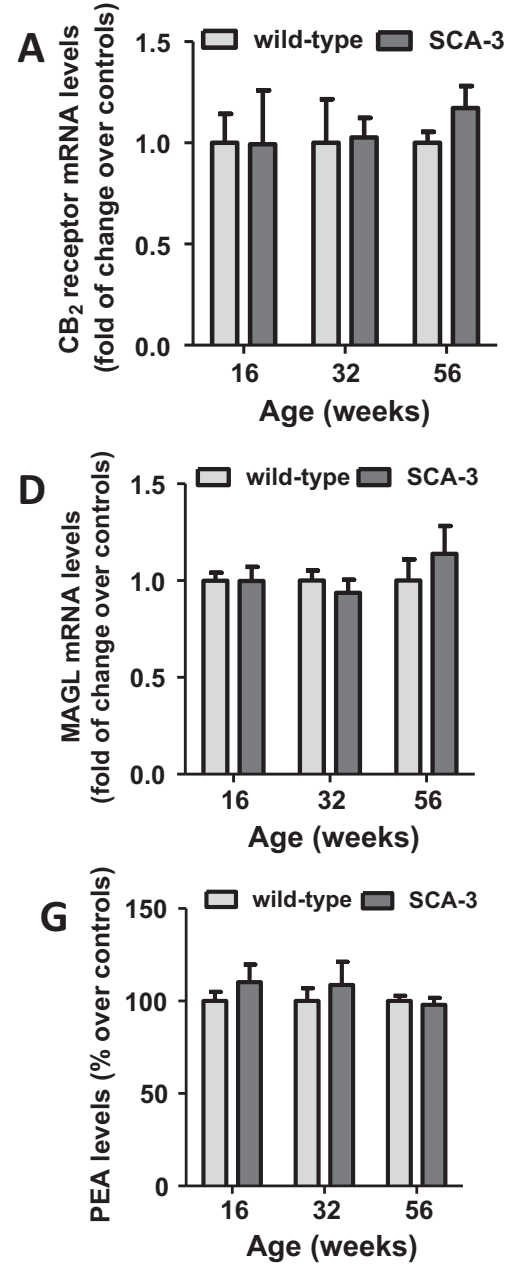
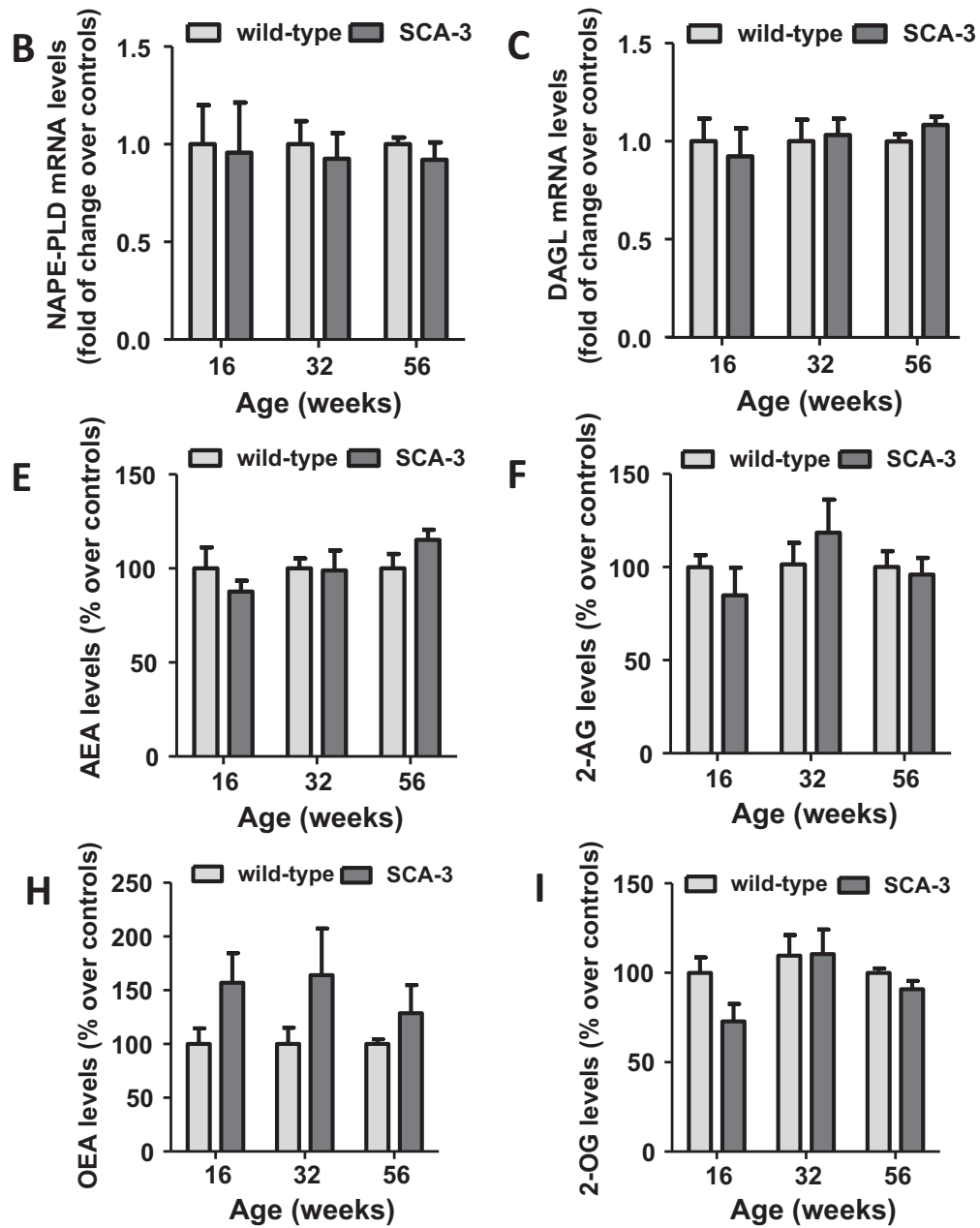

Fig. 9. Biochemical analysis of endocannabinoid genes, and levels of endocannabinoids and related signaling lipids in the cerebellum of SCA-3 transgenic and wild-type mice: Panels $A-D$ : qPCR analysis of the $\mathrm{CB}_{2}$ receptor and the NAPE-PLD, DAGL and MAGL enzymes in the cerebellum of SCA-3 transgenic and wild-type mice at different ages in disease progression. Panels E-I: LC-MS analysis of the levels of anandamide (AEA) and its related congeners palmitoylethanolamide (PEA) and oleylethanolamide (OEA), as well as 2-arachidonoylglycerol (2-AG) and its congener 2-oleylglycerol (2-OG) in the cerebellum of SCA-3 transgenic and wild-type mice at different ages in disease progression. In all cases, values are expressed as mean \pm SEM of 5-6 subjects per group. Data were assessed by Student's $t$-test.

mice. For example, an elevated $\mathrm{CB}_{1}$ receptor-mediated signaling has been associated with the occurrence of cerebellum-related symptoms like limb ataxia in naïve animals in previous pharmacological studies (DeSanty and Dar, 2001; Patel and Hillard, 2001). A similar conclusion emerged from the studies relating mutations in ABHD12 with the occurrence of ataxia (Fiskerstrand et al., 2010; Chen et al., 2013), as it is expected that loss-of-function mutations in this enzyme should elevate 2-AG levels in the CNS (at least in those areas having lower MAGL activity), which, through an excess of $\mathrm{CB}_{1}$ receptor activation, could explain the appearance of ataxia. These data have been reproduced in mice with genetic ablation of ABHD12 (Blankman et al., 2013). Therefore, we assume that the elevation of $\mathrm{CB}_{1}$ receptors we found in the Purkinje cell layer of SCA-3 transgenic mice, predominantly in terminals of the basket cells, may also have an influence in the occurrence of ataxia, independently of the role of this receptor in slowdown the progression of the disease. It is also interesting to mention a recent study by Wang et al. (2013), who described a deficient $\mathrm{CB}_{1}$ receptor signaling in a murine model of ataxia generated by mutations in the $\alpha 2 \delta 2$ subunit of the voltagedependent calcium channel, which mainly affected the Purkinje cells. However, this murine model may be more reminiscent of SCA-6, which is the SCA type with greater deterioration of Purkinje cells, derived from the naturallyoccurring mutation in the $\alpha 1 \mathrm{~A}$ subunit of the same channel.

Lastly, the relevance of the abovementioned changes in specific endocannabinoid elements for either disease progression or specific symptoms, is that they may be possibly corrected by different pharmacological approaches. One possibility is to develop therapies for alleviating specific symptoms, for example, to reduce ataxia by blocking the elevated $\mathrm{CB}_{1}$ receptors found in the Purkinje cell layer. Previous pharmacological studies support these potential benefits on specific symptoms (DeSanty and Dar, 2001; Patel and Hillard, 2001; Stephens, 2016). However, as found in other 

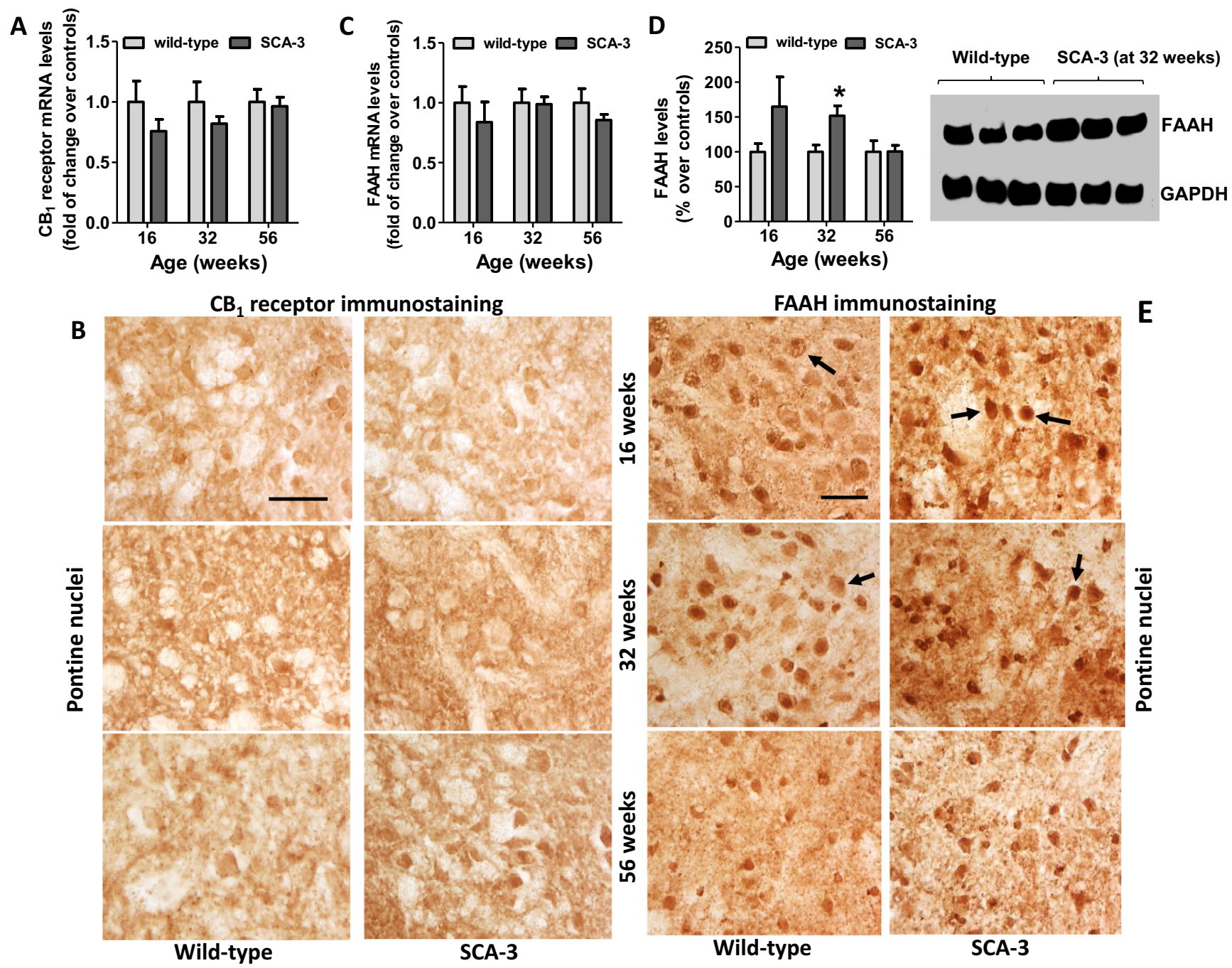

Fig. 10. Histological and biochemical analysis of the $\mathrm{CB}_{1}$ receptor and the FAAH enzyme in the brainstem of SCA-3 transgenic and wild-type mice: Panel A: qPCR analysis of the $\mathrm{CB}_{1}$ receptor in the brainstem of SCA-3 transgenic and wild-type mice at different ages in disease progression. Panel $B$ : Immunostaining for the $\mathrm{CB}_{1}$ receptor in the pontine nuclei of SCA-3 transgenic and wild-type mice at different ages in disease progression $(\mathrm{bar}=50 \mu \mathrm{m})$. Panels $C$ and $D:$ qPCR analysis and Western blot quantification (with a representative blot) of the FAAH enzyme in the brainstem of SCA-3 transgenic and wild-type mice at different ages in disease progression. Panel E: Immunostaining for the FAAH enzyme in the pontine nuclei of SCA-3 transgenic and wild-type mice at different ages in disease progression (bar $=50 \mu \mathrm{m})$. Arrows indicate the presence of FAAHimmunostained cells demonstrating an elevated immunolabeling in SCA-3 transgenic mice compared to wild-type animals. In all cases, values are expressed as mean \pm SEM of more than six subjects per group. Data were assessed by Student's $t$-test $\left({ }^{*} p<0.05\right.$ versus wild-type animals).

neurodegenerative disorders, e.g. Parkinson's disease (Fernández-Ruiz et al., 2011), the best option to get an effective and sustained symptom relief with cannabinoid-based therapies is the control of disease progression, something for which cannabinoids are particularly enabled (Fernández-Ruiz et al., 2015). In this sense, our data support that the activation of $\mathrm{CB}_{1}$ receptors may be beneficial for preserving the neurons of the dentate nucleus, whose $\mathrm{CB}_{1}$ receptor signaling is hampered. Such therapy would be aimed at correcting the dysregulation of endocannabinoid signaling by enhancing $\mathrm{CB}_{1}$ receptor function, assuming that the dysregulation represents a maladaptive response that contributes to disease progression. This may be also the case of elevated FAAH-mediated hydrolysis of endocannabinoids found in some brainstem nuclei, which would be also a maladaptive response contributing to disease progres- sion. The option in this case may be to selectively inhibit FAAH enzyme with the purpose of enhancing the levels of endocannabinoids and their protective function. In both cases, enhancing $\mathrm{CB}_{1}$ receptor signaling or inhibiting FAAH enzyme would be addressed to correct the changes in both targets that are contributing to pathogenesis. However, the neuroprotective properties derived from the manipulation of the endocannabinoid signaling may also include to enhance specific responses of this signaling that represent adaptive mechanisms aimed at restoring neuronal homeostasis against different damaging stimuli (Di Marzo et al., 2015). We expected this may be the case of $\mathrm{CB}_{2}$ receptor-mediated signaling, given that up-regulatory responses aimed at preserving neurons against inflammatory events have been identified for most of neurodegenerative disorders (Fernández-Ruiz et al., 2007, 2010, 2011) including 

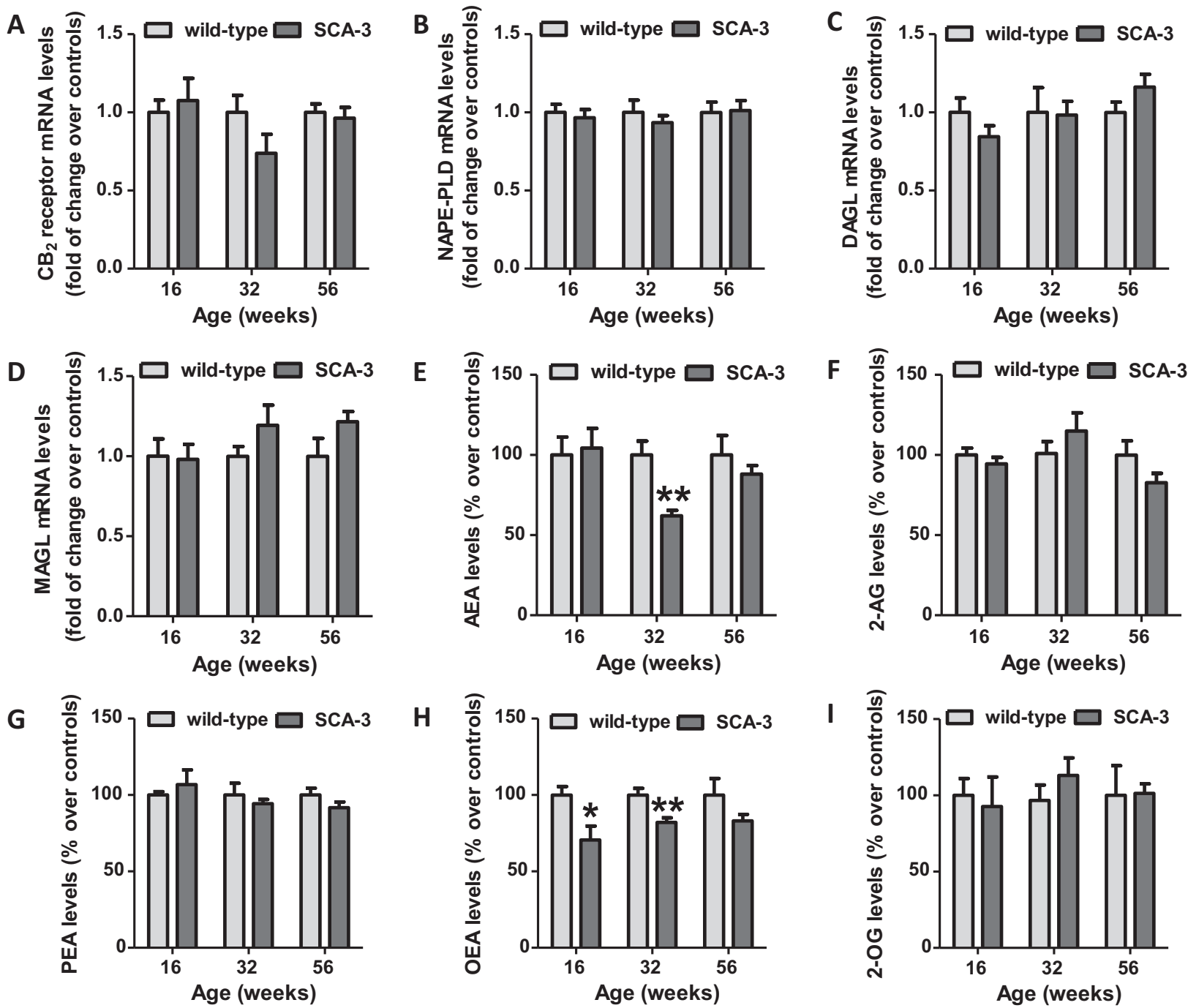

Fig. 11. Biochemical analysis of endocannabinoid genes, and levels of endocannabinoids and related signaling lipids in the brainstem of SCA-3 transgenic and wild-type mice: Panels $A-D$ : qPCR analysis of the $\mathrm{CB}_{2}$ receptor and the NAPE-PLD, DAGL and MAGL enzymes in the brainstem of SCA-3 transgenic and wild-type mice at different ages in disease progression. Panels E-l: LC-MS analysis of the levels of anandamide (AEA) and its related congeners palmitoylethanolamide (PEA) and oleylethanolamide (OEA), as well as 2-arachidonoylglycerol (2-AG) and its congener 2-oleylglycerol (2-OG) in the brainstem of SCA-3 transgenic and wild-type mice at different ages in disease progression. In all cases, values are expressed as mean \pm SEM of 5-6 subjects per group. Data were assessed by Student's $t$-test $\left({ }^{\star} p<0.05,{ }^{* *} p<0.01\right.$ versus wild-type animals).

SCAs in our previous studies in post-mortem tissues from patients (Rodríguez-Cueto et al., 2014a). We had also considered the interest of a specific interaction of the $\mathrm{CB}_{2}$ receptor with the heat shock protein 90 (Hsp90), as has been recently found in eye cells ( $\mathrm{He}$ et al., 2012), given that inhibition of this molecular chaperone has been found to be beneficial in SCA-3 transgenic mice (Silva-Fernandes et al., 2014). However, we were unable to find any evidence of $\mathrm{CB}_{2}$ receptor up-regulation in the two highly vulnerable areas investigated in these SCA-3 transgenic mice, in which the levels of $C_{2}$ receptors remained permanently unaffected. As mentioned above, it is possible that the lack of response of the $\mathrm{CB}_{2}$ receptor derives from the absence of reactive gliosis in these areas, a fact that had been already described in this model (Silva-Fernandes et al., 2014). Another adaptive response frequently elicited by the endocannabinoid signaling in response to damage is the elevation in the generation of endocannabinoids. This has been found in numerous chronic neurodegenerative disorders (Fernández-Ruiz et al., 2010) and our study represented the first time that the levels of these signaling lipids were analyzed in SCA-3 tissues. However, we were unable to demonstrate that endocannabinoid levels are significantly elevated in the brain of SCA-3 transgenic mice. Indeed, the only change we were able to detect was a reduction in the brainstem which, as mentioned above, possibly derived from an increased degradation by the elevated FAAH levels in this structure, then contributing to disease progression rather than being an adaptive protective response.

\section{CONCLUSIONS}

Our results in SCA-3 mutant mice confirm a possible dysregulation in the endocannabinoid signaling system 
in the most important brain structures affected in this type of ataxia, suggesting that a pharmacological manipulation addressed to correct the changes in the endocannabinoid signaling could be a promising option in SCA-3. We are presently conducting pharmacological experiments to validate this hypothesis.

\section{STATEMENT OF COMPETING INTEREST}

Authors declare that they have no conflicts of interest in relation with this submission.

Acknowledgments-This study has been supported by MICINN (SAF2009-11847 and SAF2015-68580-C2-1-R), CIBERNED (CB06/05/0089), "Fundación Eugenio Rodríguez Pascual" and the Research and Education Component of the Advancing a Healthier Wisconsin Endowment at the Medical College of Wisconsin. Carmen Rodríguez-Cueto was a predoctoral fellow supported by FPI Program-Ministry of Science. Authors are indebted to Yolanda García-Movellán for administrative support.

\section{REFERENCES}

Alves S, Nascimento-Ferreira I, Dufour N, Hassig R, Auregan G, Nóbrega C, et al. (2010) Silencing ataxin-3 mitigates degeneration in a rat model of Machado-Joseph disease: no role for wild-type ataxin-3? Hum Mol Genet 19:2380-2394.

Blankman JL, Long JZ, Trauger SA, Siuzdak G, Cravatt BF (2013) ABHD12 controls brain lysophosphatidylserine pathways that are deregulated in a murine model of the neurodegenerative disease PHARC. Proc Natl Acad Sci USA 110:1500-1505.

Chen DH, Naydenov A, Blankman JL, Mefford HC, Davis M, Sul Y, et al. (2013) Two novel mutations in ABHD12: expansion of the mutation spectrum in PHARC and assessment of their functional effects. Hum Mutat 34:1672-1678.

Chou AH, Chen SY, Yeh TH, Weng YH, Wang HL (2011) HDAC inhibitor sodium butyrate reverses transcriptional downregulation and ameliorates ataxic symptoms in a transgenic mouse model of SCA3. Neurobiol Dis 41:481-488.

Chou AH, Yeh TH, Ouyang P, Chen YL, Chen SY, Wang HL (2008) Polyglutamine-expanded ataxin-3 causes cerebellar dysfunction of SCA3 transgenic mice by inducing transcriptional dysregulation. Neurobiol Dis 31:89-101.

Cristino L, de Petrocellis L, Pryce G, Baker D, Guglielmotti V, Di Marzo V (2006) Immunohistochemical localization of cannabinoid type 1 and vanilloid transient receptor potential vanilloid type 1 receptors in the mouse brain. Neuroscience 139:1405-1415.

Deleye S, Verhaeghe J, wyffels L, Dedeurwaerdere S, Stroobants S, Staelens S (2014) Towards a reproducible protocol for repetitive and semi-quantitative rat brain imaging with (18) F-FDG: exemplified in a memantine pharmacological challenge. Neuroimage 96:276-287.

DeSanty KP, Dar MS (2001) Cannabinoid-induced motor incoordination through the cerebellar CB1 receptor in mice. Pharmacol Biochem Behav 69:251-259.

Di Marzo V, Stella N, Zimmer A (2015) Endocannabinoid signalling and the deteriorating brain. Nat Rev Neurosci 16:30-42.

Durr A (2010) Autosomal dominant cerebellar ataxias: polyglutamine expansions and beyond. Lancet Neurol 9:885-894.

Evert BO, Vogt IR, Vieira-Saecker AM, Ozimek L, de Vos RA, Brunt ER, et al. (2003) Gene expression profiling in ataxin-3 expressing cell lines reveals distinct effects of normal and mutant ataxin-3. J Neuropathol Exp Neurol 62:1006-1018.

Evert BO, Schelhaas J, Fleischer H, de Vos RA, Brunt ER, Stenzel W, et al. (2006) Neuronal intranuclear inclusions, dysregulation of cytokine expression and cell death in spinocerebellar ataxia type 3. Clin Neuropathol 25:272-281.
Fernández-Ruiz J, García C, Sagredo O, Gómez-Ruiz M, de Lago E (2010) The endocannabinoid system as a target for the treatment of neuronal damage. Expert Opin Ther Targets 14:387-404.

Fernández-Ruiz J, Moreno-Martet M, Rodríguez-Cueto C, PalomoGaro C, Gómez-Cañas M, Valdeolivas S, et al. (2011) Prospects for cannabinoid therapies in basal ganglia disorders. $\mathrm{Br} J$ Pharmacol 163:1365-1378.

Fernández-Ruiz J, Moro MA, Martínez-Orgado J (2015) Cannabinoids in neurodegenerative disorders and stroke/brain trauma: from preclinical models to clinical applications. Neurotherapeutics 12:793-806.

Fernández-Ruiz J, Romero J, Velasco G, Tolón RM, Ramos JA, Guzmán M (2007) Cannabinoid CB2 receptor: a new target for controlling neural cell survival? Trends Pharmacol Sci 28:39-45.

Fernández-Ruiz J, Sagredo O, Pazos MR, García MC, Pertwee RG, Mechoulam R, et al. (2013) Cannabidiol for neurodegenerative disorders: important new clinical applications for this phytocannabinoid? Br J Clin Pharmacol 75:323-333.

Fiskerstrand T, H'mida-Ben Brahim D, Johansson S, M'zahem A, Haukanes BI, Drouot N, et al. (2010) Mutations in ABHD12 cause the neurodegenerative disease PHARC: An inborn error of endocannabinoid metabolism. Am J Hum Genet 87:410-417.

Fratkin JD, Vig PJ (2012) Neuropathology of degenerative ataxias. Handb Clin Neurol 103:111-125.

Gould VFC (2012) Mouse models of spinocerebellar ataxia type 3 (Machado-Joseph disease). Neurotherapeutics 9:285-296.

He F, Kumar A, Song ZH (2012) Heat shock protein 90 is an essential molecular chaperone for CB2 cannabinoid receptor-mediated signaling in trabecular meshwork cells. Mol Vis 18:2839-2846.

Ishikawa K, Mizusawa H, Fujita T, Ohkoshi N, Doi M, Komatsuzaki Y, et al. (1995) Calbindin-D 28k immunoreactivity in the cerebellum of spinocerebellar degeneration. J Neurol Sci 129:179-185.

Jacobi H, Reetz K, du Montcel ST, Bauer P, Mariotti C, Nanetti L, et al. (2013) Biological and clinical characteristics of individuals at risk for spinocerebellar ataxia types 1, 2, 3, and 6 in the longitudinal RISCA study: analysis of baseline data. Lancet Neurol 12:650-658.

Klockgether T (2011) Update on degenerative ataxias. Curr Opin Neurol 24:339-345.

Koeppen $\mathrm{AH}$ (2005) The pathogenesis of spinocerebellar ataxia. Cerebellum 4:62-73.

Koeppen AH, Ramirez RL, Bjork ST, Bauer P, Feustel PJ (2013) The reciprocal cerebellar circuitry in human hereditary ataxia. Cerebellum 12:493-503.

Matilla-Dueñas A (2012) Machado-Joseph disease and other rare spinocerebellar ataxias. Adv Exp Med Biol 724:172-188.

Matilla-Dueñas A, Corral-Juan M, Volpini V, Sánchez I (2012) The spinocerebellar ataxias: clinical aspects and molecular genetics. Adv Exp Med Biol 724:351-374.

Menzies FM, Huebener J, Renna M, Bonin M, Riess O, Rubinsztein DC (2010) Autophagy induction reduces mutant ataxin-3 levels and toxicity in a mouse model of spinocerebellar ataxia type 3 . Brain 133:93-104.

Murata Y, Yamaguchi S, Kawakami H, Imon Y, Maruyama H, Sakai $T$, et al. (1998) Characteristic magnetic resonance imaging findings in Machado-Joseph disease. Arch Neurol 55:33-37.

Nascimento-Ferreira I, Nóbrega C, Vasconcelos-Ferreira A, Onofre I, Albuquerque D, Aveleira C, et al. (2013) Beclin 1 mitigates motor and neuropathological deficits in genetic mouse models of Machado-Joseph disease. Brain 136:2173-2188.

Nogami M, Takatsu A, Endo N, Ishiyama I (1998) Immunohistochemistry of neuron-specific enolase in neurons of the medulla oblongata from human autopsies. Acta Histochem 100:371-382.

Orr HT (2012) Cell biology of spinocerebellar ataxia. J Cell Biol 197:167-177.

Patel S, Hillard CJ (2001) Cannabinoid CB1 receptor agonists produce cerebellar dysfunction in mice. J Pharmacol Exp Ther 297:629-637.

Patel S, Wohlfeil ER, Rademacher DJ, Carrier EJ, Perry LJ, Kundu A, et al. (2003) The general anesthetic propofol increases brain 
$\mathrm{N}$-arachidonylethanolamine (anandamide) content and inhibits fatty acid amide hydrolase. Br J Pharmacol 139:1005-1013.

Paulson HL, Perez MK, Trottier Y, Trojanowski JQ, Subramony SH, Das SS, et al. (1997) Intranuclear inclusions of expanded polyglutamine protein in spinocerebellar ataxia type 3. Neuron 19:333-344.

Paulson H (2012) Machado-Joseph disease/spinocerebellar ataxia type 3. Handb Clin Neurol 103:437-449.

Riess O, Rüb U, Pastore A, Bauer P, Schöls L (2008) SCA3: neurological features, pathogenesis and animal models. Cerebellum 7:125-137.

Rodríguez-Cueto C, Benito C, Fernández-Ruiz J, Romero J, Hernández ML, Gómez-Ruiz M (2014a) Changes in $\mathrm{CB}_{1}$ and $\mathrm{CB}_{2}$ receptors in the post-mortem cerebellum of humans affected by spinocerebellar ataxias. Brit J Pharmacol 171:1472-1489.

Rodríguez-Cueto C, Benito C, Romero J, Hernández ML, GómezRuiz M, Fernández-Ruiz J (2014b) Endocannabinoid-hydrolysing enzymes in the post-mortem cerebellum of humans affected by hereditary autosomal dominant ataxias. Pathobiology 81:149-159.

Romero J, Hillard CJ, Calero M, Rábano A (2002) Fatty acid amide hydrolase localization in the human central nervous system: an immunohistochemical study. Mol Brain Res 100:85-93.

Rüb U, Schöls L, Paulson H, Auburger G, Kermer P, Jen JC, et al. (2013) Clinical features, neurogenetics and neuropathology of the polyglutamine spinocerebellar ataxias type 1, 2, 3, 6 and 7. Prog Neurobiol 104:38-66.

Seidel K, Siswanto S, Brunt ER, den Dunnen W, Korf HW, Rüb U (2012) Brain pathology of spinocerebellar ataxias. Acta Neuropathol 124:1-21.
Seidel K, Siswanto S, Fredrich M, Bouzrou M, Brunt ER, van Leeuwen FW, et al. (2016) Polyglutamine aggregation in Huntington's disease and spinocerebellar ataxia type 3: similar mechanisms in aggregate formation. Neuropathol Appl Neurobiol 42:153-166.

Silva-Fernandes A, Duarte-Silva S, Neves-Carvalho A, Amorim M, Soares-Cunha C, Oliveira P, et al. (2014) Chronic treatment with 17-DMAG improves balance and coordination in a new mouse model of Machado-Joseph disease. Neurotherapeutics 11:433-449.

Soong B, Cheng C, Liu R, Shan D (1997) Machado-Joseph disease: clinical, molecular, and metabolic characterization in Chinese kindreds. Ann Neurol 41:446-452.

Stephens GJ (2016) Does modulation of the endocannabinoid system have potential therapeutic utility in cerebellar ataxia. J Physiol 594:4631-4641.

Suárez J, Bermúdez-Silva FJ, Mackie K, Ledent C, Zimmer A, Cravatt BF, et al. (2008) Immunohistochemical description of the endogenous cannabinoid system in the rat cerebellum and functionally related nuclei. J Comp Neurol 509:400-421.

Taniwaki T, Sakai T, Kobayashi T, Kuwabara Y, Otsuka M, Ichiya Y, et al. (1997) Positron emission tomography (PET) in MachadoJoseph disease. J Neurol Sci 145:63-67.

Taroni F, DiDonato S (2004) Pathways to motor incoordination: the inherited ataxias. Nat Rev Neurosci 5:641-655.

Wang X, Whalley BJ, Stephens GJ (2013) The du(2J) mouse model of ataxia and absence epilepsy has deficient cannabinoid $\mathrm{CB}_{1}$ receptor-mediated signalling. J Physiol 591:3919-3933. 